\title{
Developing multiscale and integrative nature-people scenarios using the Nature Futures Framework
}

Laura M. Pereira ${ }^{1,2,3}$ (D) Kathryn K. Davies ${ }^{4}$ | Eefje den Belder ${ }^{5}$ Simon Ferrier
Sylvia Karlsson-Vinkhuyzen Tanya Lazarova $^{10}$ | Federica Ravera ${ }^{19,20}$ | Nakul Chettri ${ }^{21}$ | William W. L. Cheung ${ }^{22}$ Rob J. J. Hendriks ${ }^{23,24}$ | Grigoriy Kolomytsev ${ }^{25}$ | Paul Leadley ${ }^{26}$ | Jean-Paul Metzger ${ }^{27}$ Karachepone N. Ninan ${ }^{28}$ | Ramon Pichs ${ }^{29}$ | Alexander Popp ${ }^{30}$ | Carlo Rondinini ${ }^{31}$ | Isabel Rosa $^{32}$ | Detlef van Vuuren ${ }^{3,10}$ | Carolyn J. Lundquist ${ }^{4,33}$

${ }^{1}$ Centre for Complex Systems in Transition, Stellenbosch University, Matieland, South Africa; ${ }^{2}$ Stockholm Resilience Centre, Stockholm University, Stockholm, Sweden; ${ }^{3}$ Copernicus Institute of Sustainable Development, Utrecht University, Utrecht, The Netherlands; ${ }^{4}$ National Institute of Water \& Atmospheric Research, Hamilton, New Zealand; ${ }^{5}$ Agrosystems Research, Wageningen University and Research, Wageningen, The Netherlands; ${ }^{6} \mathrm{CSIRO}$ Land and Water, Canberra, ACT, Australia; ${ }^{7}$ Public Administration and Policy Group, Wageningen University and Research, Wageningen, The Netherlands; ${ }^{8} \mathrm{German}$ Centre for Integrative Biodiversity Research (iDiv) Halle-Jena-Leipzig, Leipzig, Germany; ${ }^{9}$ Institute of Biology, Martin Luther University Halle-Wittenberg, Halle (Saale), Germany; ${ }^{10}$ PBL Netherlands Environmental Assessment Agency, Den Haag, The Netherlands; ${ }^{11}$ Museo Argentino de Ciencias Naturales Bernardino Rivadavia-CONICET, Buenos Aires, Argentina; ${ }^{12} \mathrm{CIBIO}$ (Research Centre in Biodiversity and Genetic Resources)-InBIO (Research Network in Biodiversity and Evolutionary Biology), Universidade do Porto, Vairão, Portugal; ${ }^{13}$ National Institute for Rural Development and Panchayati Raj, Hyderabad, India; ${ }^{14}$ Environmental Systems Analyses Group, Wageningen University and Research, Wageningen, The Netherlands; ${ }^{15}$ Instituto Geociências, Universidade Federal Minas Gerais, Belo Horizonte, Brazil; ${ }^{16}$ Manaaki Whenua Landcare Research, Auckland, New Zealand; ${ }^{17}$ CoKnow Consulting, Jesewitz, Germany; ${ }^{18}$ Research Unit for Environmental Science \& Management, North-West University, Potchefstroom, South Africa; ${ }^{19}$ Chair in Agroecology and Food Systems University of Victoria, Central University of Catalunya, Vic, Spain; ${ }^{20}$ Department of Geography, University of Girona, Girona, Spain; ${ }^{21}$ International Centre for Integrated Mountain Development, Kathmandu, Nepal; ${ }^{22}$ Institute for the Oceans and Flsheries, The University of British Columbia, Vancouver, BC, Canada; ${ }^{23}$ Department of Strategy, Knowledge and Innovation, Nature-Inclusive Society Group, Ministry of Agriculture, Nature and Food Quality, The Hague, The Netherlands; ${ }^{24}$ Institute for Water and Wetland Research, Radboud University, Nijmegen, The Netherlands; ${ }^{25}$ Department of Animal Monitoring and Conservation, I.I. Schmalhausen Institute of Zoology NAS of Ukraine, Kyiv, Ukraine; ${ }^{26}$ Ecologie Systématique Evolution, Bâtiment 360 , Univ. Paris-Sud, AgroParisTech, CNRS, Université Paris-Saclay, Orsay, France; ${ }^{27}$ Department of Ecology, Institute of Biosciences, University of Sao Paulo, Sao Paulo, Brazil; ${ }^{28}$ Centre for Economics, Environment and Society, Bangalore, India; ${ }^{29}$ Centre for World Economy Studies (CIEM), Havana, Cuba; ${ }^{30}$ Potsdam Institute for Climate Impact Research (PIK), Member of the Leibniz Association, Potsdam, Germany; ${ }^{31}$ Global Mammal Assessment programme, Department of Biology and Biotechnologies, Sapienza University of Rome, Rome, Italy; ${ }^{32}$ School of Natural Sciences, Bangor University, Bangor, UK and ${ }^{33}$ Institute of Marine Science, University of Auckland, Auckland, New Zealand

Correspondence

Laura M. Pereira

Email: pereira.laura18@gmail.com

\section{Funding information}

Svenska Forskningsrådet Formas, Grant/Award Number: 2018-02371; Royal Society of New Zealand, Grant/Award Number: CSG-NIW1701; National Research Foundation of South Africa,

\section{Abstract}

1. Scientists have repeatedly argued that transformative, multiscale global scenarios are needed as tools in the quest to halt the decline of biodiversity and achieve sustainability goals.

2. As a first step towards achieving this, the researchers who participated in the scenarios and models expert group of the Intergovernmental Science-Policy Platform on Biodiversity and Ecosystem Services (IPBES) entered into an iterative,

This is an open access article under the terms of the Creative Commons Attribution License, which permits use, distribution and reproduction in any medium, provided the original work is properly cited.

(c) 2020 The Authors. People and Nature published by John Wiley \& Sons Ltd on behalf of British Ecological Society 
Grant/Award Number: 115300; Ministerie van Buitenlandse Zaken

Handling Editor: Benis Egoh participatory process that led to the development of the Nature Futures Framework (NFF).

3. The NFF is a heuristic tool that captures diverse, positive relationships of humans with nature in the form of a triangle. It can be used both as a boundary object for continuously opening up more plural perspectives in the creation of desirable nature scenarios and as an actionable framework for developing consistent nature scenarios across multiple scales.

4. Here we describe the methods employed to develop the NFF and how it fits into a longer term process to create transformative, multiscale scenarios for nature. We argue that the contribution of the NFF is twofold: (a) its ability to hold a plurality of perspectives on what is desirable, which enables the development of joint goals and visions and recognizes the possible convergence and synergies of measures to achieve these visions and (b), its multiscale functionality for elaborating scenarios and models that can inform decision-making at relevant levels, making it applicable across specific places and perspectives on nature.

5. If humanity is to achieve its goal of a more sustainable and prosperous future rooted in a flourishing nature, it is critical to open up a space for more plural perspectives of human-nature relationships. As the global community sets out to develop new goals for biodiversity, the NFF can be used as a navigation tool helping to make diverse, desirable futures possible.

\section{KEYWORDS}

biodiversity, futures, IPBES, models, nature, scenarios, values

\section{1 | INTRODUCTION}

The rapid decline in the state of nature and its clear links to the prosperity of human societies has led scientists to argue that transformative change is required in how societies relate to nature. The first Global Assessment by the Intergovernmental SciencePolicy Platform on Biodiversity and Ecosystem Services (IPBES) and the recent special report on Global Warming of $1.5^{\circ} \mathrm{C}$ of the Intergovernmental Panel on Climate Change (IPCC) both argue that a sustainable world cannot be achieved without transformative systemic change of our societies (IPBES, 2019; IPCC, 2018). Achieving such a change requires identifying visions, pathways and plans that can help people navigate away from undesirable futures and towards desirable ones (Balvanera et al., 2017; Bennett et al., 2016; Peterson et al., 2018). The urgency to reframe the future of human societies' relationships with nature has become even clearer since the outbreak of the Covid-19 pandemic, which is sure to enter the global negotiation agendas for the next biodiversity and climate change targets that will take place in 2021. Decisions on how to catalyse transformative change can be supported by the co-production of visions, scenarios and pathways that are collectively and transparently developed and are made accessible to all interested stakeholders (Pereira, Asrar, et al., 2019). New types of globally relevant scenarios and futures are urgently needed that not only provide an orientation of what diverse possibilities might be achievable, but also to catalyse the movement towards these more desirable futures for people and the planet, in all their plurality (Luederitz, Abson, Audet, \& Lang, 2017).

In this paper, we address the question of how a new set of scenarios that respond to these needs can be developed. We outline the systematic steps to develop such scenarios that have been made by a group of experts who participated in the IPBES scenarios and models expert group, and we explain the methodology of each element of the process in detail to illustrate how the process differs from the development of previous global environmental scenarios. A key outcome of the process thus far has been the creation of the Nature Futures Framework (NFF), a heuristic tool based on the diverse, positive relationships that humans have with nature, whilst at the same time offering a structure for consistency in the scenarios and models that use it. The NFF enables the co-production of novel scenarios that incorporate diverse interventions towards positive future trajectories for nature and nature's contributions to people. In our discussion, we analyse the contribution of the NFF both as a boundary object to open up more plural perspectives in the creation of nature scenarios and as an actionable framework for developing consistent nature scenarios across multiple scales and levels, whilst enabling this plurality to flourish. 
We conclude with a call to arms for the research community to mobilize and help in moving this agenda forward. We see a broad sweep of the research community interested in the future of nature and its contributions to people as the main audience for this paper. By describing here the background, methodological process and rationale underpinning the NFF, we hope that it will inspire other researchers-ranging from those interested in participatory co-production processes with local communities through to global integrated assessment modellers-to integrate the NFF into their own activities. We set out specifics for how we envision this joint venture could be undertaken in the discussion.

\section{1 | New scenarios for nature}

The Intergovernmental Science-Policy Platform on Biodiversity and Ecosystem Services was established in 2012 by 94 member states of the United Nations to become the leading intergovernmental body for assessing the state of nature and nature's contributions to people (NCP), as well as options for action. The IPBES conceptual framework illustrates that the ways that nature, biodiversity and ecosystem services are conceived and valued vary across cultures and societies (Díaz et al., 2015). People ascribe different types of values to nature, and its contributions to a good quality of life are often perceived and conceptualized by people in different and sometimes conflicting ways (e.g. as the environment, Mother Earth, natural resources, natural capital from which people derive ecosystem services, our biological community etc.; IPBES, 2015). Furthermore, people ascribe multiple values to the same natural entity (e.g. a landscape can simultaneously be seen as a provider of food and medicine, a good site for mineral exploitation, important for water supply, a habitat for wildlife, a beautiful place or a sacred space; IPBES, 2015). Being able to recognize this plurality and address it in assessments, policies, models and scenarios is a key goal of IPBES.

Scenarios are recognized as powerful tools to examine how different pathways of future human development and policy choices could affect nature and nature's contributions to people (NCP; Ferrier et al., 2016; Harrison et al., 2018; Rosa et al., 2017). However, to date, most scenarios for global environmental assessments have explored impacts of society on nature, such as biodiversity loss, but have not explored the role of nature and related policies in driving development (Ferrier et al., 2016; Millennium Ecosystem Assessment, 2005; Pereira et al., 2010; Saito et al., 2019). Indeed, the variety of connections between people and nature, and how these vary across the world, have mostly been ignored in scenario processes, and the linkages between nature and nature's contributions to people have been underexplored (Cumming et al., 2005; Johnson et al., 2020; Rosa et al., 2017). Furthermore, most existing global assessment scenarios have only been conducted at aggregated global scales, in which local and regional variation, tele-connections and cross-scale dynamics have not been well captured (IPBES, 2016; Obermeister, 2019; Rosa et al., 2017).
Addressing issues of power and rationality in how scenarios are framed, and ensuring an equitable inclusion of voices, especially those of the most marginalized to frame matters of concern is another core challenge (Cairns \& Wright, 2019). In relation to nature conservation, IPBES have highlighted the particular importance of including indigenous and local knowledge (ILK), which has long been marginalized or invisible in global scenarios and models. It is therefore increasingly clear that there is a need for new global scenarios for nature (Kok et al., 2016; Rosa et al., 2017; Wyborn et al., 2020).

The scenarios that are currently widely used in global environmental assessments are the Shared Socio-Economic pathways (SSPs). The SSPs were developed by the climate change community to help outline potential socio-economic trends that would influence how climate change manifests in the future (O'Neill et al., 2014, 2017). Whilst they have been successful in both the science and policy domain and in unifying different areas of research, the SSPs have limitations in their applicability to biodiversity and nature research. Firstly, they say little about desirable outcomes for nature and its contributions to people, making it difficult to incorporate biodiversity-specific interventions into models (IPBES, 2016; Rosa et al., 2017). This limits their ability to inspire change (Bennett et al., 2016; IPBES, 2016; Pereira, Sitas, Ravera, Jimenez-Aceituno, \& Merrie, 2019). Second, these scenarios are expert-led and have not been legitimized through a co-production process in which a plurality of perspectives are included (Duncan et al., 2018; Kok et al., 2016; Tengö et al., 2017). Finally, the SSPs focus on their use only as inputs to a scientific process (O'Neill et al., 2017). However, in global assessments scenarios also act as boundary objects that are used to mobilize action, and as tools for building future literacy amongst stakeholders (Kok et al., 2016; Tengö et al., 2017). These concerns highlight the need for new, participatory nature scenarios that can inform decision-making and inspire action.

Following from the IPBES methodological assessment of scenarios and models of biodiversity and ecosystem services (IPBES, 2016), the former IPBES scenarios and models expert group set out a research strategy to address some of the above concerns and initiated the development of multiscale scenarios for nature based on pluralistic desirable visions for human relationships with nature (Rosa et al., 2017). These scenarios should be produced at and applicable across multiple scales through a process that includes a diversity of stakeholder voices and values, and explicitly include pathways that enable humanity to meet the desired 2050 vision under the Convention on Biological Diversity (CBD) of 'Living in harmony with nature' where 'biodiversity is valued, conserved, restored and wisely used, maintaining ecosystem services, sustaining a healthy planet and delivering benefits essential for all people' (UNEP, 2010: para 11). Central to this process was the research question of how to develop these new scenarios in a way that addresses the gaps identified in other scenarios in order to support the work programme of IPBES. In this paper, we answer this question by documenting the iterative process that was undertaken by the IPBES scenarios and models expert 
group from 2016 to 2019. Presenting methodological approaches in scenario development is important to ensure scientific credibility as well as legitimacy (Sarkki et al., 2014), but it also ensures replicability where others are able to build on and further contribute to the approach, and critique it. In the following section, we present the outputs of the process to date, including a description of the visions, stakeholder feedback and framework development, and also outline the plan for the development of scenarios that can be used by modellers and practitioners.

\section{2 | METHODOLOGICAL APPROACH}

There is an emerging agreement that sustainability challenges require new ways of knowledge production and decision-making, including the involvement of actors from outside academia into the research process in order to integrate the best available knowledge, reconcile values and preferences, as well as create ownership for problems and solution options (Laing \& Wallis, 2016; Obermeister, 2017). As the development of the new nature scenarios is taking place under the auspices of an intergovernmental science-policy platform, such a transdisciplinary approach was required. However, doing transdisciplinary research is not straightforward and requires a deep level of reflection and learning as well as an openness to change direction in response to the needs of diverse participants (Norström et al., 2020; Pereira, Frantzeskaki, et al., 2019). As such, the methodological approach of the scenario development process needed to navigate this complex reality whilst resulting in a usable outcome.

There is currently a debate as to whether ensuring credibility, relevance and legitimacy are of the utmost importance to policy in assessment processes (Sarkki et al., 2015) or whether applicability, comprehensiveness, timing and accessibility are of more relevance (Dunn \& Laing, 2017). At the same time, there are trade-offs and constraints to any science-policy process (Sarkki et al., 2014). Whilst being able to leverage the inclusion, representivity and legitimacy offered by intergovernmental platforms, this can also come with certain constraints, including limited time and funding to undertake specific tasks (see Sarkki et al., 2014), and sometimes a lack of interdisciplinary expertise and other forms of knowledge (Harrison et al., 2018; Obermeister, 2017; Vadrot, Jetzkowitz, \& Stringer, 2016; Vadrot, Rankovic, Lapeyre, Aubert, \& Laurans, 2018). For the expert group, designing a process that could overcome these constraints, whilst producing diverse multiscale positive scenarios for nature was a key challenge. A first step was to ensure a common language of terms within the research group (Box 1). A second step was the development of core principles. Despite these considerations, the overall approach, especially in terms of including stakeholder voices in the process, was a combination of systematic outreach to a broad diversity of stakeholders across all continents and levels of governance, and using additional opportunities as they occurred in order to reach more voices. This process was still constrained by the limited human and budget resources that were available.
We employed three core principles for the approach: co-production, interactive iteration and pluralism. Co-production is increasingly seen as an important process in sustainability science as it enables the harnessing of multiple viewpoints and creates buy-in to a process (Norström et al., 2020). A core aspect of the sciencepolicy interface is the dynamic interaction between stakeholders and scientists that iterates over time, allowing for learning and readjustments (Priess \& Hauck, 2014; Sarkki et al., 2015). Finally, according to the IPBES conceptual framework, a plurality of perspectives is core to the platform (Díaz et al., 2015). The subsequent approach was largely informed by the multiple evidence base approach where an enriched picture of understanding serves a starting point for further knowledge generation, triangulation and assessment (Tengö, Brondizio, Elmqvist, Malmer, \& Spierenburg, 2014; Tengö et al., 2017).

Next, we outline the iterative process (in the form of phases) and outcomes that resulted at each step, and lay out what is planned to continue to build on the process in the future. This iterative approach is how we went about answering the research question of how to create a new set of scenarios that are diverse, desirable, and multiscale. It has taken time and learning along the way has been a key part of this process, which is also why we seek to document it in this paper. In the discussion section, we situate the findings from this process within the existing literature and critically examine the contribution that the NFF could make in its aim for improved nature scenarios for decision-making in the post 2020 agenda.

\section{1 | Iterative phases}

The scenario development process consisted of five distinct methodological phases (Figure 1): Phase (i) visioning and storyline development through a participatory workshop (Section 3.1); Phase (ii) elaboration through stakeholder engagement to address gaps in the visions (Section 3.2); Phase (iii) formulation of the NFF based on analysis of the elaborated visions by the expert group (Section 3.3); Phase (iv) further refinement of the NFF through stakeholder engagement (Section 3.4); and finally, Phase (v) consolidation of scenario narratives that can be used by diverse research communities, including modellers (Section 3.5). In the results section, we present the methods that were used as well as the outputs that arose from each of the steps. We discuss the implications of the method and the future development of the NFF scenarios in Section 4.

\section{2 | Analysis}

At each step in the co-production process, information was documented and recorded. For the analysis of the information captured from the stakeholder engagement exercises (Phases i, ii and iv), an approach similar to the Nominal Group Technique (NGT) was 


\section{BOX 1 Glossary of terms}

Drivers-The external factors that cause change in nature, anthropogenic assets, nature's contributions to people and a good quality of life. They include institutions and governance systems and other indirect drivers, and direct drivers (both natural and anthropogenic; IPBES, 2016).

Future wheels-A graphic method similar to a collectively brainstormed mind-map that identifies direct and indirect future consequences or impacts of a particular change or development (Glenn, 2009).

Nature Futures Framework (NFF)-A heuristic that captures diverse, positive values for human-nature relationships in a triangular space (the NFF triangle; see Figure 5). We consider three main ways of valuing nature at each of the vertices (nature for nature, nature for society and nature as culture). The NFF builds on the three values of nature (intrinsic, instrumental and relational values, respectively) identified by the IPBES and repurposes it to make it actionable for the modelling and scenarios community. The NFF triangle illustrates how it is possible to emphasize a complex mixture of values for appreciating nature depending where in the triangle you are situated and thus allows for a plurality of perspectives to be held in different times, contexts and spaces. As such, the NFF approach and the triangle can be used both as a boundary object for continuously opening up more plural perspectives in the creation of nature scenarios (when referring just to the NFF triangle) and as an actionable framework for developing consistent scenarios and models across multiple scales and levels when referring to the overall process captured in Figure 1.

Pathways-Different strategies for moving from the current situation towards a desired future vision or set of specified targets. They are purposive courses of actions that build on each other, from short-term to long-term actions into broader transformation (Ferguson, Frantzeskaki, \& Brown, 2013; Frantzeskaki, Loorbach, \& Meadowcroft, 2012; Wise et al., 2014). The Three Horizons approach is often used to define such pathways in future visioning processes (Sharpe, Hodgson, Leicester, Lyon, \& Fazey, 2016).

Scenarios-Plausible and often simplified descriptions of how the future may develop, based on a coherent and internally consistent set of assumptions about key driving forces and relationships (Millennium Ecosystem Assessment, 2005). A scenario skeleton is a simplified outline of a scenario.

Seeds-Current positive and inspiring initiatives that hold potential to shape a more just, prosperous and sustainable future. They can be initiatives (social, technological, economic, or social-ecological ways of thinking or doing) that exist, at least in prototype form, and that represent a diversity of worldviews, values, and regions, but are not currently dominant or prominent in the world (Bennett et al., 2016).

Three Horizons approach-A simple, graphical and collaborative approach to build pathways for desirable futures based on a structured and guided dialogue considered along a temporal axis (now, near future, and far future): the first horizon is a business as usual scenario, the second horizon represents the necessary actions to move from the present to the desired future and the third horizon represents emerging paradigms, ideas and innovations for a desirable future (Sharpe, 2013; Sharpe et al., 2016; Figure 6).

Values-A principle or core belief underpinning rules and moral judgements. Values as principles vary from one culture to another and also between individuals and groups (IPBES/4/INF/13).

Visions-A desirable state in the future and therefore, a component of scenarios (the possible future states), demarcated from predictions (likely future states) and pathways (that lead up to the vision). Visions are usually seen as a desirable image of the future and can be defined as a compelling, inspiring statement of the preferred future that the authors and those who subscribe to the vision want to create (Wiek \& Iwaniec, 2014).

Visioning-'The process of creating a vision, that is, a representation of a desirable future state, as opposed to scenario building (possible future states), forecasting (likely future states), and backcasting (pathways to desirable future states)' (Wiek \& Iwaniec, 2014, p. 497).

chosen to organize the discussion process whereby participants are asked to individually reflect and generate ideas based on predetermined questions (Duncan, 2004). Subsequently, they collectively prioritize the ideas and suggestions issued by the group members (Clemen \& Winkler, 1999; Harvey \& Holmes, 2012). The process allowed us to combine individual and collective reflection, to explore novel concepts, and eventually generate a list of priorities (Coker et al., 2014; Rankin et al., 2016). There is some criticism of NGT in that it is a version of the Delphi method where the feedback step takes place during a face-to-face meeting of experts instead of filling in anonymized questionnaires. For such group settings, Ayyub (2001) highlights the following as potential limitations: socially reinforced conformity within the group, dominance of strong-minded or strident individuals, group motive of 
FIGURE 1 The five main methodological phases used for the development of Nature Future Scenarios, which are described in-depth in Section 3. This overall process illustrates how the Nature Futures Framework evolved. (Source: Authors' own)

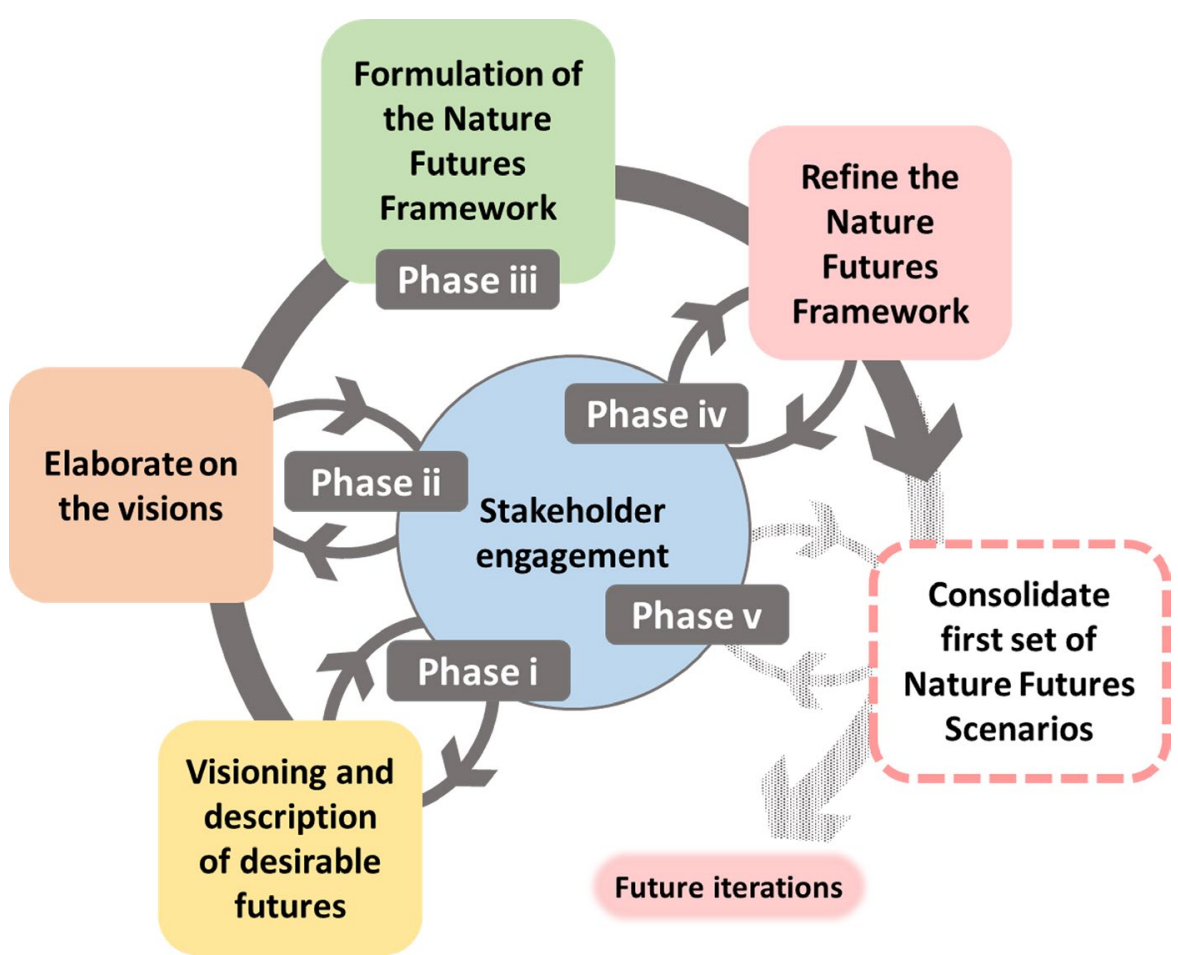

quickly reaching agreement and group-reinforced bias due to common background of group members. To mitigate these potential limitations, the reflection process was guided by facilitators to ensure that individual personalities and other characteristics did not exert a disproportionate effect on outcomes. Multiple iterations of individual reflections followed by group discussion and synthesis is a valuable technique to avoid confrontation while allowing for a wider range of perspectives to be aired (Dalkey \& Helmer, 1963). Multiple rounds of iterative feedback between multiple groups also allows for the attenuation of institutional and psychological biases (e.g. Hannagan \& Larimer, 2010).

The description of the visions from Phase i were written in conjunction with all group members to ensure all aspects were covered and the mapping of the visions across a variety of characteristics was inductively undertaken as part of the workshop process. All the participants brainstormed and prioritized a set of characteristics that they thought were most relevant for describing the core aspects of the visions and these were then tested across all of the visions to see whether they were feasible. The final characteristics were chosen based on those that were most relevant to all the visions, and the visions were mapped according to group consensus, as a result of this inductive group process (see Table S1). More information on the specific analysis, including figures of the visions mapped across different characteristics, can be found in Lundquist et al. (2017).

During each stakeholder workshop (Phases ii and iv), notes were taken and these data were then recorded in a spreadsheet under thematic codes and analysed to see where there were overlaps and where gaps could be identified (see Table S3). Finally, expert opinion was used to analyse how the visions and stakeholder inputs could be optimally used to derive model-relevant scenarios that remained true to the co-produced, plural and multiscale nature of the undertaking. Through an inductive process that involved group analysis of the data in the visions and clustering into thematic components, the three dimensions of the triangle were derived (see PBL, 2018 for a full documentation of the expert workshop process undertaken in Phase iii). In Section 3 below, we present the results of how this iterative process was undertaken (Figure 1) as well as the outcomes at each of the phases that fed into subsequent phases.

\section{3 | Ethical considerations}

As this research was not undertaken through a university, there is no ethical clearance number. However, we endeavoured to follow all ethical guidelines in the involvement of human participants during the course of this research. The work presented was performed in accordance with the declaration of Helsinki and is in conformity with ethical standards of research. The authors have ensured that the information presented in this paper is either sourced from materials available in the public domain as a result of consent from participants or based on anonymous opt-ins to the research process by participants. Chatham House rules are applied in all workshops and nothing is attributed to any specific individual. All participants are authors of the publicly available workshop reports from which information was extracted for Phases i and iii (Lundquist et al., 2017; PBL, 2018). For the stakeholder engagement in Phases ii and iv, all participants were invited to opt in with an explicit explanation that their responses would be used as direct input to the future visions, 
but that all information would be anonymized. At the beginning of each stakeholder engagement process, we obtained verbal consent from all participants present that the outputs from the session may be used in research publications, but that no personal data would be used. The only personal details recorded were of the participants' nationality for regional representation purposes. More information on the source of data for each workshop is available in Supporting Information S2.

\section{3 | METHODS AND RESULTS: DEVELOPING NATURE FUTURES}

We use Figure 1 to structure this section and discuss the different methods and their results by each phase. A more in-depth description of the specific methods used in Phases i, ii, iii and iv is provided in Supporting Information S2.

\section{1 | Phase i: Visioning and storyline development}

The process began with a global participatory visioning workshop in Auckland, New Zealand, in September 2017 with 73 participants from 31 countries and representing all UN regions (Africa, Asia and the Pacific, Latin America and the Caribbean, Eastern Europe, Western Europe and others). The selection of stakeholders was a rigorous and iterative process that aimed to ensure as wide a range of geographies and perspectives as possible, drawing from a wide set of IPBES stakeholders (see Lundquist et al., 2017, Appendix A1 for the full selection criteria and description of the process). The final group included representatives from intergovernmental organizations, indigenous peoples from New Zealand, Europe, North America and Latin America, national government, non-governmental organizations, academia and the private sector and with a range of expertise on biodiversity topics, from urban development to agriculture to fisheries. The main objective of the workshop was the

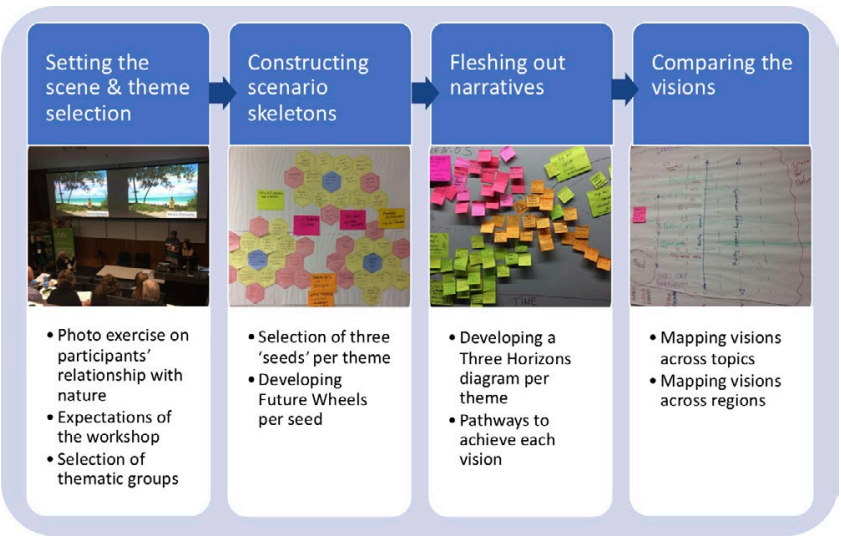

FIGURE 2 Four steps of the Intergovernmental Science-Policy Platform on Biodiversity and Ecosystem Services Nature Futures Visioning workshop in Auckland (Source: Adapted from Lundquist et al., 2017) development of positive visions of nature and their associated storylines. It followed an approach designed to produce bottom-up, divergent visions of the future (Pereira, Hichert, Hamann, Preiser, \& Biggs, 2018). The approach was selected with the intention of creating a space in which participants could think creatively to develop an inspired and powerful set of visions, grounded in existing 'Seeds' (see Box 1). The workshop process consisted of four steps (see Figure 2 and Lundquist et al., 2017, Appendix A2 for a detailed description of the workshop methodology). It is important to note that even though there was an explicit desire to include as many perspectives as possible, there is a clear bias in that only individuals who in some way prioritize and value nature are inclined to spend a full week formulating positive nature futures. The concerns of adequate representivity in a global undertaking such as this are paramount and will be picked up in the discussion.

The aim of the first step of the workshop was to set the scene and organize participants into thematic groups. In breakout groups, participants discussed themes that should be captured in future nature scenarios and then in plenary agreed on seven thematic, self-organized groups on freshwater, food, inclusive economics, urban-rural flows, indigenous and local knowledge, nature's dynamics and oceans. As these themes were brainstormed with the participants, they emphasize what those in the room thought were the most important thematic areas for discussion. Extending away from the thematic areas of focus into more holistic narratives for the development of scenarios was therefore acknowledged as a challenge that the team would face further into the process.

During the second step of the workshop, participants constructed scenario skeletons using three existing initiatives ('Seeds') that they believed would contribute to a better future that reversed the negative trends in their respective themes (Bennett et al., 2016, Box 1). In the third step, participants worked on fleshing out the narratives and exploring possible pathways to achieving the visions using the Three Horizons approach (Sharpe et al., 2016; Figure 6). This process was used to refine the visions, but did not develop specific timelines for change. As a result of these three steps, seven visions (i.e. potential Nature Futures) emerged (Table 1). These visions differ from scenarios in that they are representations of explicitly desirable futures, but do not describe pathways by which they each emerged from a baseline. As the method was designed to emphasize desirable futures, none of the descriptions are dystopian; rather different aspects of nature and its contributions to people emerge across the different visions.

Desired futures of peoples' relationship with nature varied substantially across these visions (Table 1). Some visions emphasize the indirect and intangible benefits of biodiversity, such as in Urban Rural Flows, Nature's Dynamics and Culture, while others emphasize the direct uses of nature, such as in Food Production. Acknowledging local ecosystem service flows and the development of multifunctional landscapes is an important component of Urban Rural Flows, Water, Culture and Prosperity. Others emphasize the management of global ecosystem service flows or the segregation of spatial uses of ecosystems, such as Urban Rural Flows, Nature's Dynamics and Marine. 
TAB LE 1 Seven visions of positive Nature Futures that emerged from the Auckland workshop (adapted from Lundquist et al., 2017)

\begin{tabular}{|c|c|c|}
\hline & & Image of seeds (Source: Mary Brake, \\
\hline & & Reflection Graphics; Dave Leigh, \\
\hline $\begin{array}{l}\text { Name of vision } \\
\text { (shortened title) }\end{array}$ & Description & $\begin{array}{l}\text { Emphasise Ltd.; Pepper Lindgren- } \\
\text { Streicher, Pepper Curry Design) }\end{array}$ \\
\hline
\end{tabular}

Nature-based inclusive prosperity (Prosperity)
This vision illustrates a world based on reconstructing global governance and institutional mechanisms in order to recharacterize economic drivers to include externalities and incentivize sustainable and natural resource use and sustain richly diverse cultures, societies and nature into the future
Sustainable food systems (Food Production)
This vision illustrates a world where global food production systems are re-engineered, emphasizing sustainable supply chains and benefit sharing mechanism in place between producers, traders, transporters and retailers, grounded on biodiversity-rich food production that supports local and indigenous communities
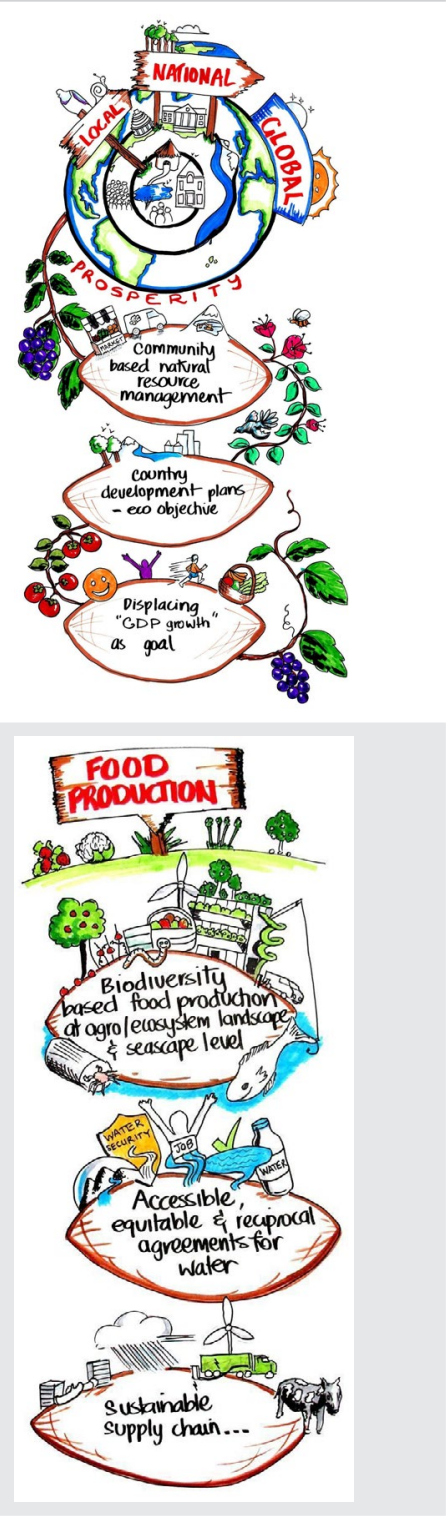

ReFooding and ReWilding the urban Rural flows (Urban Rural Flows)
This vision illustrates a world where urban and rural communities are reconnected with nature, achieved through ReGoverning to improve governance systems, ReFooding to reinstate localized ecosystem service flows and ReWilding solutions to free up space for nature across rural and urban areas

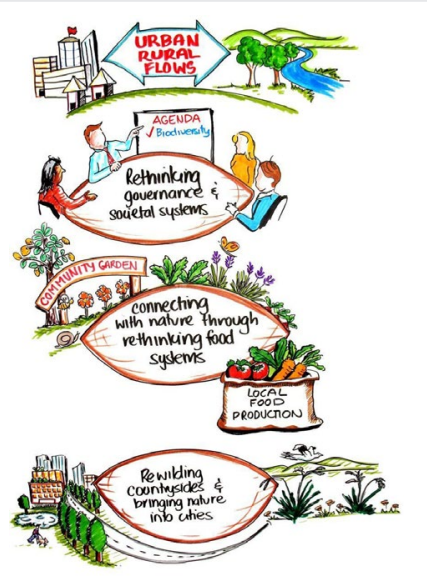


TABLE 1 (Continued)

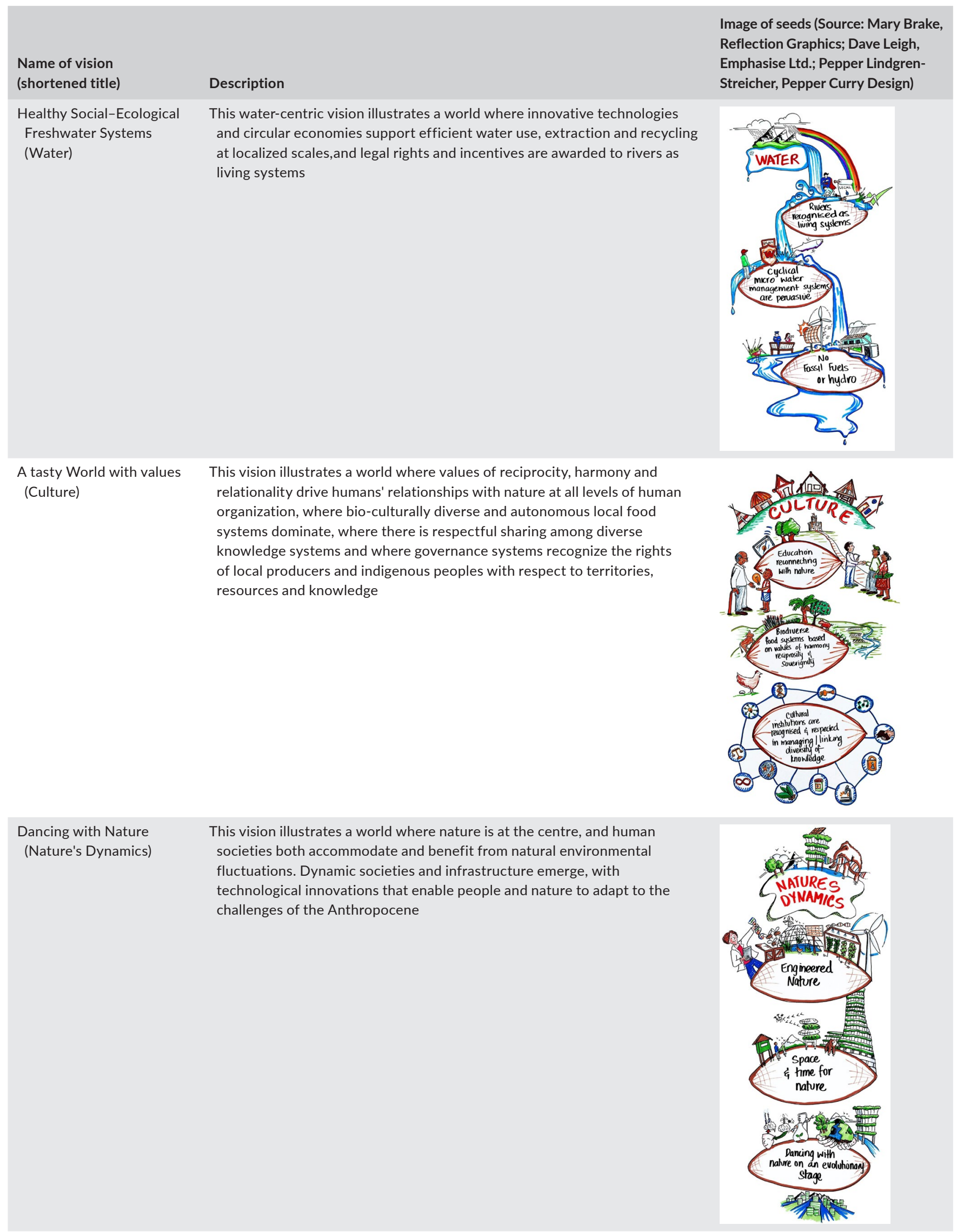


TABLE 1 (Continued)

\begin{tabular}{|c|c|c|}
\hline $\begin{array}{l}\text { Name of vision } \\
\text { (shortened title) }\end{array}$ & Description & $\begin{array}{l}\text { Image of seeds (Source: Mary Brake, } \\
\text { Reflection Graphics; Dave Leigh, } \\
\text { Emphasise Ltd.; Pepper Lindgren- } \\
\text { Streicher, Pepper Curry Design) }\end{array}$ \\
\hline $\begin{array}{l}\text { Healthy oceans, happy } \\
\text { communities (Marine) }\end{array}$ & $\begin{array}{l}\text { This ocean-centric vision illustrates a world where the high seas are closed to } \\
\text { resource extraction, and coastal ecosystems provide a wealth of ecosystem } \\
\text { services, supported by long-term sustainability strategies by governments } \\
\text { and businesses that empower local-based sustainable co-management } \\
\text { practices. Novel technologies support behavioural change to lower impact } \\
\text { diets and increase food production }\end{array}$ & (2) \\
\hline
\end{tabular}

During the fourth and final step, participants re-organized themselves into different sub-groups to map the visions across topics that they decided were the most relevant for identifying similarities and differences between the visions. These topics included (Lundquist et al., 2017; Table S1):

- State of biodiversity

- Value of nature

- Management of nature

- Governance systems

- Production and consumption of ecosystem services

- Socio-economic development

- Use of technology

- Lifestyles

The sub-groups mapped the visions across the different topics, which helped to identify commonalities and differences between them (see examples of use in Figure 3; Table S1). The visions were then compared across regions (Africa, Asia, Europe and North America, Latin America, Oceania), so that the experts present from these regions could reflect on how existing positive actions for biodiversity, infrastructure or other social, political or economic actors specific to a region might facilitate or impede the implementation of particular visions (Table S2).

Shared themes across multiple visions include green infrastructure (see Tzoulas et al., 2007), a circular economy (see Korhonen, Honkasalo, \& Seppälä, 2018), context-dependent learning to inform environmental governance (see Armitage et al., 2018) and the equalization and reduction of humanity's global footprint (see Hoekstra \& Wiedmann, 2014) overall a more 'responsible stewardship' relationship between people and nature. All of the visions require a societal paradigm shift and significant changes in values, echoing the call for transformative change necessary for the sustainable use of natural resources (IPBES, 2019). The seven Auckland visions became starting points to inform the rest of the scenario development process, but required a lot of refinement before they could be adapted, including moving away from some of the thematic foci to more holistic descriptions of nature.

\subsection{Phase ii: Elaboration of the visions through stakeholder engagement}

As the Auckland visions were developed by a small group of stakeholders, a series of further stakeholder engagement processes were conducted. The main aim of these sessions was to test how well the visions resonated with a broader group of people, how best to communicate the visions in engagement processes and to get feedback as to what the gaps or potential inconsistencies were in the visions so that these could be accounted for in the development of the scenario narratives. These stakeholder engagements took place through ad hoc engagement in IPBES events, such as Plenaries and other meetings that brought together diverse groups of stakeholders, as described below. More information is available in Supporting Information A: Methods. 
(a)

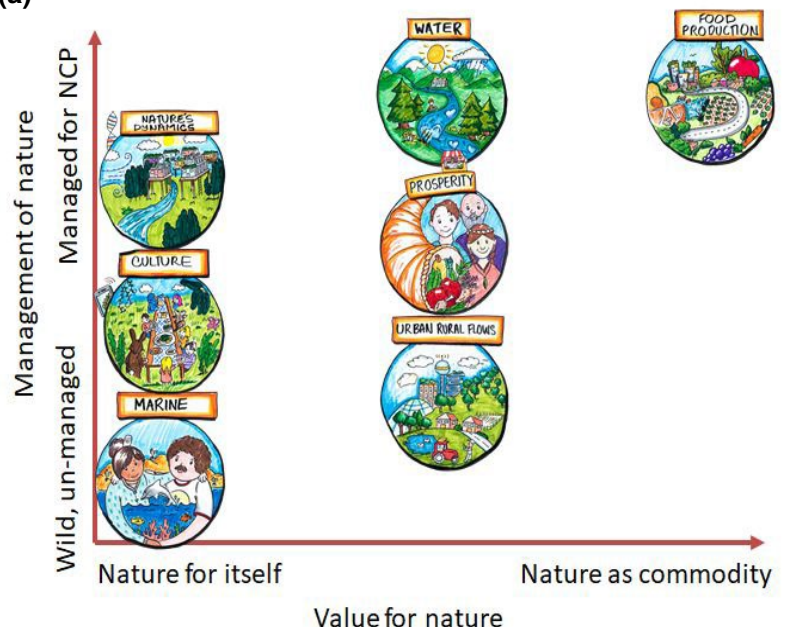

(b)

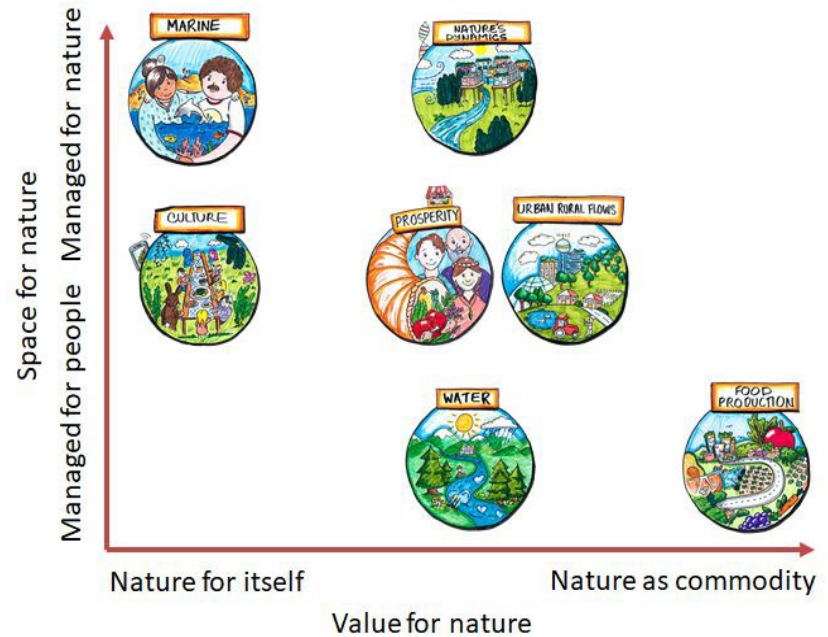

(c)

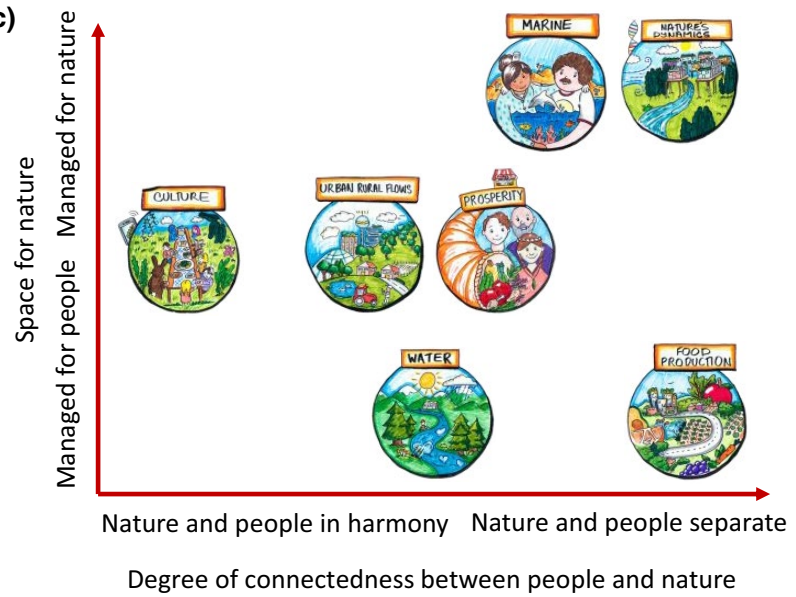

FIGURE 3 Mapping the visions across different dimensions. The axes capturing a range of values of nature from use to non-use including: (a) management of nature ( $y$ ) and value for nature ( $x$ ), (b) space for nature ( $y$ ) and value for nature ( $x$ ) and (c) space for nature $(y)$ and degree of connectedness between people and nature (x). (Adapted from Lundquist et al., 2017)

\subsection{1 | IPBES 6: Stakeholder day and plenary}

In the margins of the sixth session of the IPBES Plenary (IPBES6) and IPBES Stakeholder Day (Medellin, Colombia; 17-24 March 2018), a targeted survey was conducted to increase the 'reach' of our consultation activities. Two methods were used to generate further inputs, and materials were visualized and accessible both online and offline to facilitate accessibility and participation:

- An exhibition booth where visitors were able to add new ideas, identify gaps in visions and themes and modify or give feedback on the existing visions (Figure 4) by means of a paper survey.

- An online survey announced through both in person and social media channels.

All information from these stakeholder engagements were recorded to be used in the scenario narrative development process (Table S3).

\section{Aipbes WHAT IS YOUR VISION ON NATURE FUTURES?}

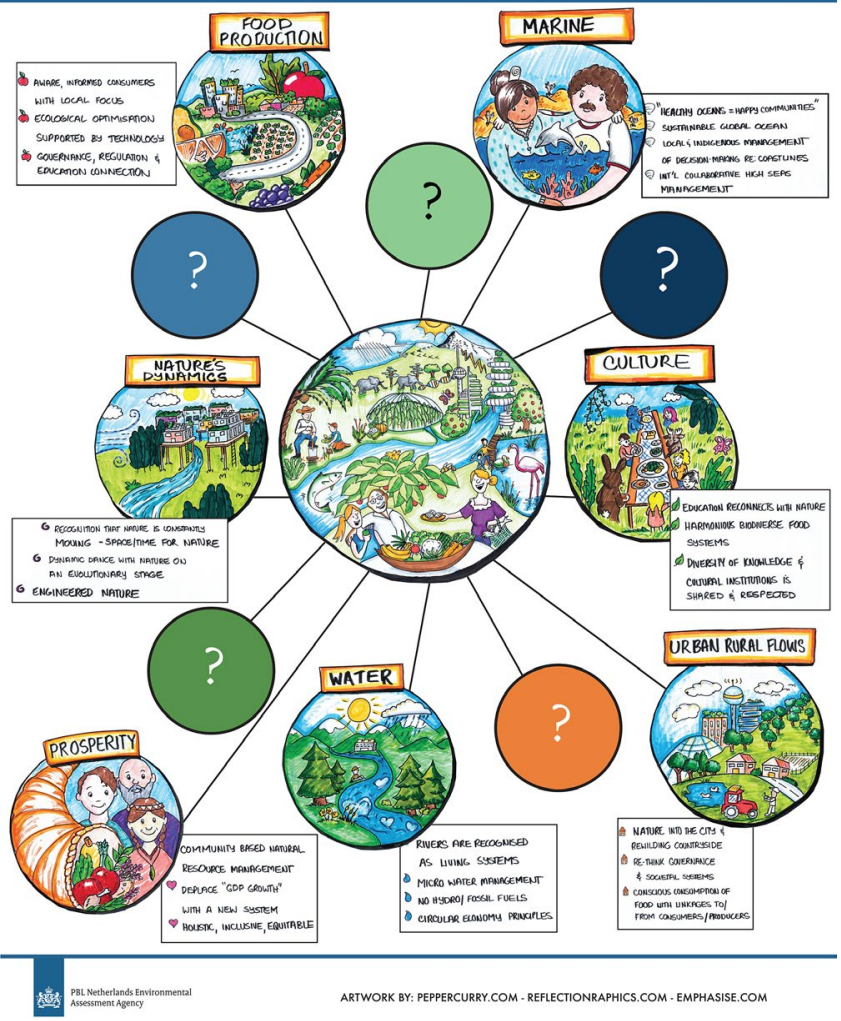

FIGURE 4 Poster used for IPBES 6 to illustrate and explain the current visions and to encourage people to suggest new areas or themes for exploration. (Source: Authors' own and images from Mary Brake, Reflection Graphics; Dave Leigh, Emphasise Ltd.; Pepper Lindgren-Streicher, Pepper Curry Design) 


\subsection{2 | Natural Capital Symposium 2018}

The seven visions were also presented at the Natural Capital Symposium, held during 19-22 March 2018 at Stanford University, where the results of the visions from the Auckland workshop were presented to attendees. This annual symposium attracts global participants from a variety of sectors and disciplines, including NGOs, business, government and academia. Key learnings included the need for approaches to align participants in a constructive process to explore and enrich visions even when time is limited, and to develop processes that work across different knowledge backgrounds, including those with limited familiarity with scenario approaches. Not all the visions resonated with stakeholders equally and it was not easy to explain the main differences between the seven visions because of the high degree of overlap in some instances. The need to differentiate between aspects of the visions was an underlying rationale in the development of the NFF in the next phase and was also a core aspect for consideration in the scenario development process.

\section{3 | Phase iii: Formulating the Nature Futures Framework}

In June 2018, an expert meeting was organized in The Hague (PBL, 2018). The objective was to develop a plan for formulating scenarios across scales based on the prior visioning process in Auckland, and to identify concrete tasks for engaging both the expert community and broader stakeholders in further co-development of the visions. In response to the feedback from the stakeholder engagement processes in Phase ii, the expert group decided that it was necessary to map out the seven visions that had been developed in Phase i to see what the fundamental overlaps, similarities and differences were. A group of scientists spent 3 days analysing the visions coming out of Phase i, and the elaborations that resulted from Phase ii, testing different parameters for mapping and categorizing them in a meaningful way (see PBL, 2018 for a full account of the workshop process). Considering that all visions were intentionally desirable visions of future human-nature relationships, and that some were narrower in geographical or ecosystem scope (e.g. covering freshwater or marine systems), it was clear that the parameters for separating them would need to be clear and consistent. After many discussions the experts came to realize that underpinning the visions were three value perspectives for how people relate to nature (Figure 5).

Building on the IPBES guidance on multiple values that identify intrinsic, instrumental and relational values for nature (IPBES, 2015), but seeking to find short and descriptive names for these perspectives they were called:

- Nature for Nature, in which nature has value in and of itself, and the preservation of nature's diversity and functions is of primary importance;

- Nature for Society, in which nature is primarily valued for the benefits or uses people derive from it, and which could lead to an optimization of multiple uses of nature and

- Nature as Culture, in which humans are perceived as an integral part of nature, and therefore what is valued is the reciprocal character of the people-nature relationship.

The NFF builds on the three values of Nature (relational, instrumental and intrinsic values) identified by the IPBES and repurposes it to make it actionable for the modelling and scenarios community. ${ }^{1}$ According to the IPBES guidance on multiple values of nature, intrinsic values refer to non-anthropocentric values associated with nature and its contributions to people and are independent of any human experience and evaluation (IPBES, 2015). Referencing Pascual et al. (2017), they refer to the inherent value of nature and its components, which is not generated by human beings. Instrumental
FIGURE 5 The Nature Futures Framework triangle with a list of some possible synonyms for the value perspectives that are used by various actors. (Source: PBL, 2018)

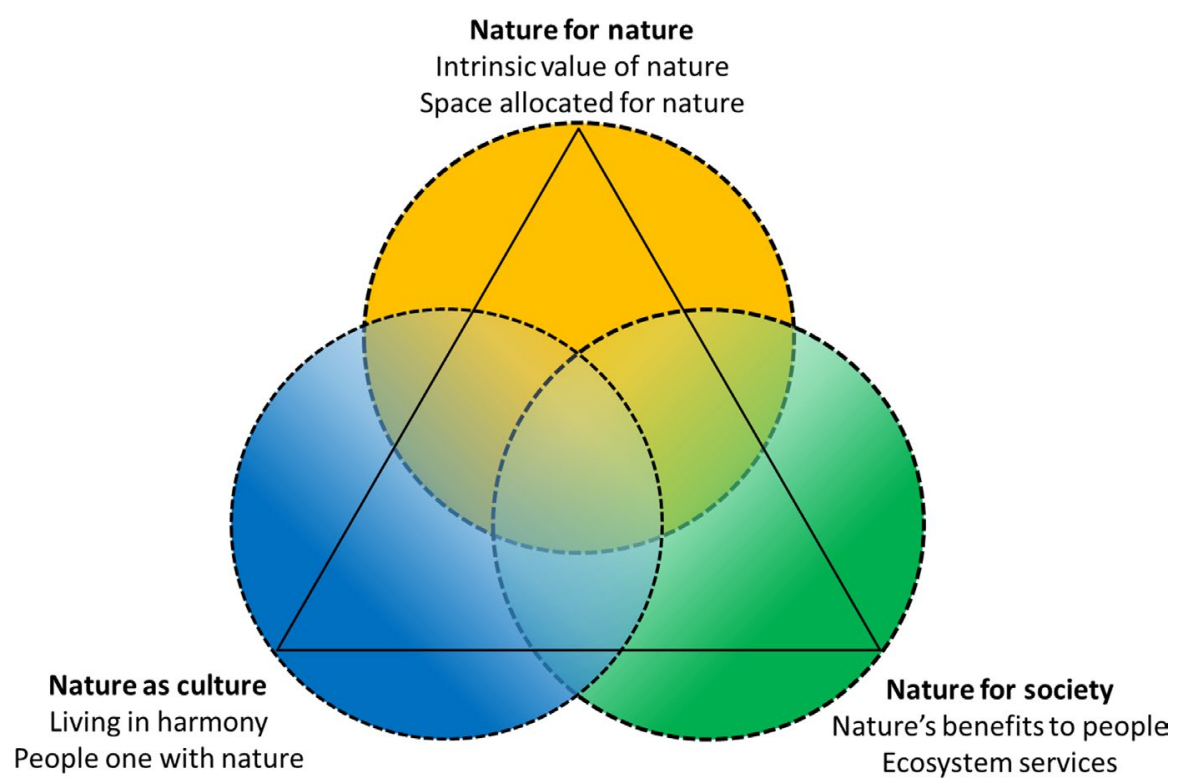

Nature for nature

Intrinsic value of nature

Space allocated for nature 
values often relate to NCP and refer to the value attributed to something as a means to achieve a particular end. Finally, relational values reflect relationships 'with natural entities to the extent that such relationships are embedded in people's identity and every day' (IPBES, 2015).

The expert group recognized the importance of elaborating on what futures in the corners and along the sides of the triangle look like (scenarios), and of identifying the transformative changes required to achieve them (pathways). The corners would therefore serve as reference points for analysing differences and convergences in actions motivated by the value positions. When combined, these plural value perspectives are more likely to be situated closer to the middle of the triangle in a way that appreciates all perspectives, and is not just dominated by one perspective. However, in reality, in order to strike that balance whilst maintaining diversity, it was recognized that some areas of the triangle will be emphasized more by some people in certain times and places compared to others. Understanding how people understood and appreciated this nuance and flexibility of the NFF was essential to the process and so further stakeholder engagement was undertaken. Important to note is also that all three value perspectives illustrate positive visions of the future human-nature relationship. The common situation of undervaluing nature that is prevalent in many societies today is not visible in the NFF.

\subsection{Phase iv: Further refinement of the NFF through stakeholder engagement}

Before moving on to develop scenario narratives for modelling using the NFF triangle, it was necessary to test how stakeholders received the framework as a clear and understandable heuristic, and whether it was a useful way to frame the complex discussion about plural nature-society value relations and whether we could start to populate scenarios of what a world would look like that emphasized aspects of the triangle's value perspectives. We thus developed a set of participatory processes for testing the NFF with a diverse group of the biodiversity community. The description of the Triangle exercise that took place in October 2018 in Bonn, Germany with a group of 42 attendees, in the margins of IPBES meetings is explained in Supporting Information S2. The aim of that exercise was to develop a method for allowing people to engage with the NFF and to see whether it was understandable to a diverse group of people. Below we describe a process undertaken during the 14th Conference of the Parties (COP) of the Convention on Biological Diversity (CBD) in 2018.

\subsection{1 | CBD COP 14: Three horizons approach}

Further stakeholder engagement was held during an interactive workshop in the Rio Conventions Pavilion at the CBD COP in Sharm El-Sheik, Egypt on 20 November 2018. Results are extracted from materials made available in the public domain by the International Institute of Sustainable Development (IISD) based on verbal consent provided by participants on-site during the event (IISD, 2018). The group exercises followed the three horizons approach (Figure 6), where participants were invited to discuss future visions and pathways to achieve them (Curry \& Hodgson, 2008; Sharpe, 2013; Sharpe et al., 2016). Participants began by creatively envisioning a more desirable future for their thematic areas (Horizon 3) and then working back to the present system (Horizon 1). Discussing Horizon 2 was the final step, representing the transition zone between the present and the future where different pathways can be articulated. The questions asked in the process were:

- Horizon 3: What is the desirable state for this value perspective in the marine/rural/urban ecosystem?

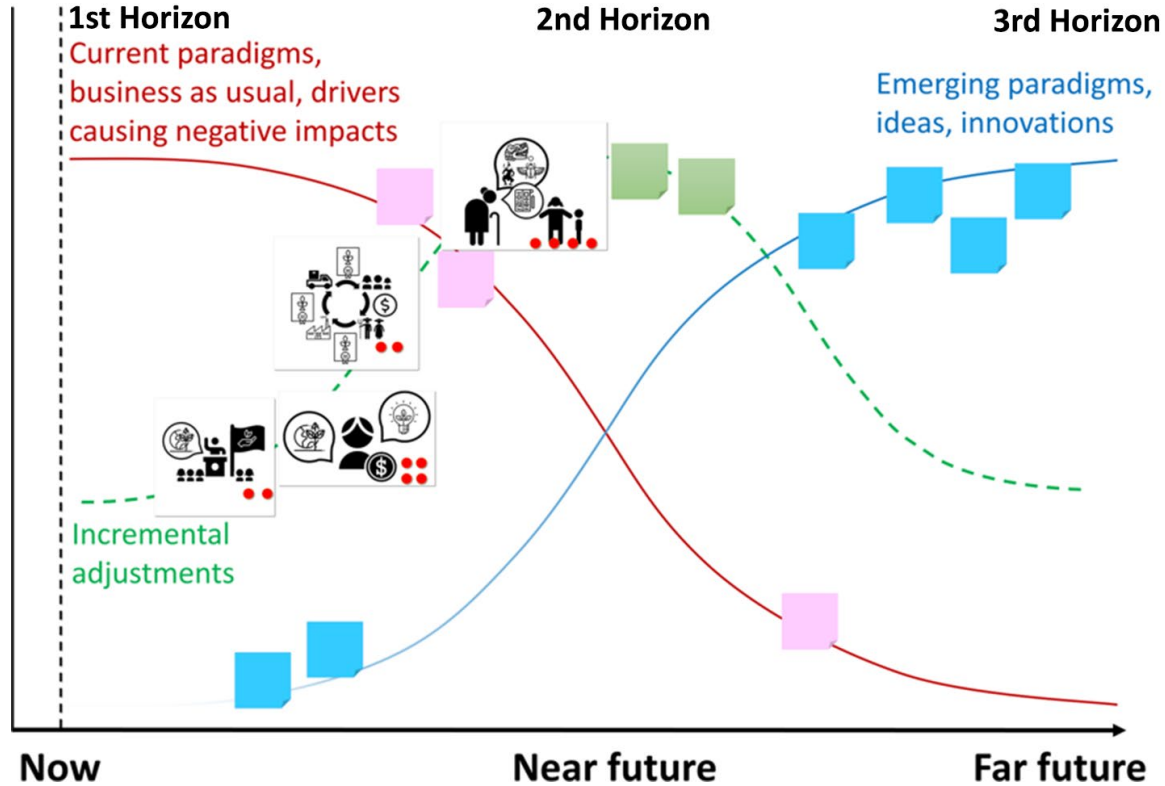

FIGURE 6 Three Horizons heuristic tool used as a method in the CBD COP 14 workshop. The red line of Horizon 1 represents the current paradigms, business as usual and drivers causing negative impacts. The blue line of Horizon 3 represents emerging paradigms, ideas and innovations for a desirable future. The green line of Horizon 2 represents the necessary actions and adjustments that are required to move from the present to the desired future. (Source: Authors' own) 
- Horizon 1: What are the most important direct and indirect drivers of change in nature, and what barriers prevent us from reaching that desirable state in the marine/urban/rural ecosystem?

- Horizon 2: What actions or policy interventions could address the obstacles and allow transitions towards the positive Nature Futures of the third horizon? (bearing in mind the drivers and barriers identified in Horizon 1)

The discussions were facilitated using a poster-sized template of the three horizons and participants were invited to note down their ideas on post-its or to use the predesigned icons and add them to the template to record their discussions (Figure 6).

This interactive exercise brought together 39 participants from 22 nations. These participants produced three sets of posters focusing on each of the three perspectives of the NFF in a marine, rural and urban environment. Based on the group discussions on the three horizons approach, Table 2 summarizes the group discussions of what a positive future for the three sectors could look like if diverse values for nature were explicitly recognized. The information from these processes were recorded (Table S3) to be used in the elaboration of the scenarios in Phase iv.

Overall, these exercises demonstrated that even when starting from different values perspectives, convergence and synergies can occur when considering the pathways towards the desired futures with the NFF. Synergies across different groups included sustainable consumption, deepening the role of technology within nature while also encouraging living in harmony with nature, and emphasizing the co-evolution of humans with nature. Participants stated that using the NFF as a starting point to make different value perspectives explicit was helpful for policymakers as it allowed them to consider different options and alternative sustainability trajectories.

\subsection{Phase v: Towards a first set of Nature Futures Scenarios}

The 7th session of the IPBES Plenary (IPBES-7, April-May 2019 in Paris, France) decided to establish a task force on scenarios and models to advance work on scenarios and models of biodiversity and ecosystem functions and services, as part of the new IPBES work programme up to 2030, which IPBES-7 approved. The mandate of the task force is to advise IPBES experts working on assessments on the use of scenarios, and to catalyse the further development by a variety of stakeholders including the modelling community, of scenarios and models for future IPBES assessments. The task force is following up on the work performed by the expert group on scenarios and models during the first work programme of IPBES (2014-2018). In order to fulfil this objective, the task force is currently developing a package of NFF-related material. A process is now underway to develop six illustrative scenarios of futures based on an extreme interpretation of the three value perspectives and the edges where they intersect. A core aspect of this process is to ensure that there is maximum diversity between the different scenarios so that we are able to capture a wide spectrum of possible futures based on plural value perspectives. Engaging the broader scientific community in these endeavours is of great importance and this will be discussed below in Section 4.3.

\subsection{Limitations and lessons}

The Nature Futures process required dealing with changes, including a change in membership of the expert group when it became an IPBES task force on scenarios and models in November 2019. Although there are multiple benefits from being able to associate with an intergovernmental platform such as IPBES, the fact that the project is not set up as a

TAB LE 2 Key highlights from the discussions in the six groups (see Table S3 for a full description)

\begin{tabular}{|c|c|c|c|}
\hline Value perspective & Marine & Rural & Urban \\
\hline Nature for Society & $\begin{array}{l}\text { Stronger enforcement of laws and } \\
\text { regulations as an important step } \\
\text { towards achieving the desired vision } \\
\text { of plastic-free, healthy oceans, } \\
\text { serving as a source of jobs and clean } \\
\text { energy }\end{array}$ & $\begin{array}{l}\text { The potential contribution of blockchain } \\
\text { technology and the adaptation of } \\
\text { agricultural practices to overcoming } \\
\text { some of the negative drivers such as bad } \\
\text { practices in agricultural production }\end{array}$ & $\begin{array}{l}\text { The need for a circular economy, } \\
\text { increased blue/green infrastructure, } \\
\text { ecotourism and incentives for urban } \\
\text { farming, which would require align- } \\
\text { ment of priorities across different } \\
\text { institutions charged with urban } \\
\text { planning }\end{array}$ \\
\hline Nature for Nature & $\begin{array}{l}\text { Ideal future is one of healthy oceans, } \\
\text { healthy coastlines and healthy } \\
\text { ecosystems, but corruption and } \\
\text { overfishing are major impediments to } \\
\text { this realization }\end{array}$ & $\begin{array}{l}\text { There is a possibility of envisioning a } \\
\text { future that excludes humans from rural } \\
\text { areas (Half Earth), but the preferred focus } \\
\text { is how to achieve a well-functioning } \\
\text { ecosystem with clean air and water. A } \\
\text { decrease in monocultures and pollution } \\
\text { are ways to contribute to this goal }\end{array}$ & $\begin{array}{l}\text { Sustainable cities with organic local } \\
\text { food production and increased overall } \\
\text { connectivity with nature as the } \\
\text { desirable future, which would require } \\
\text { new laws tax reforms, and better } \\
\text { spatial planning to ensure connectivity } \\
\text { between rural and urban areas }\end{array}$ \\
\hline Nature as Culture & $\begin{array}{l}\text { People's perception of oceans as being } \\
\text { the root of sustainability problems, } \\
\text { and the need to shift away from } \\
\text { seeing oceans as a property that can } \\
\text { be exploited as amusement parks, } \\
\text { and instead revive the spiritual } \\
\text { connections with them }\end{array}$ & $\begin{array}{l}\text { The need for a change in lifestyle and } \\
\text { education, and better management, with } \\
\text { more food diversity, eco-friendly farming } \\
\text { and increased engagement of youth. The } \\
\text { role of technology in overcoming these } \\
\text { challenges, and closing the gap between } \\
\text { urban and rural areas is key }\end{array}$ & $\begin{array}{l}\text { More equity in access to biodiverse } \\
\text { urban spaces, green buildings and } \\
\text { community gardens. There is a need } \\
\text { for new social norms, mindsets and } \\
\text { standard-setting initiatives that } \\
\text { connect cities to nature }\end{array}$ \\
\hline
\end{tabular}


regular research project brings constraints. These constraints include the specific protocols for convening groups: whilst it is extremely helpful to be able to draw on the large IPBES stakeholder community, sometimes the rules can be difficult to implement and it can become expensive to generate co-funding for non-supported members to attend meetings. As this process sits outside of a dedicated research project, the ability to mobilize funding to host stakeholder engagements has been a big limiting factor. The mandate of the task force being to 'catalyse' work means we depend on interactions with other researchers and stakeholders, and the fact that the expert group is voluntary and cannot dedicate excessive amounts of time and resources to the process are further constraints.

Within this context, a chief lesson is that creating a new generation of scenarios and models requires a commitment to participatory processes that makes those involved feel comfortable to express their viewpoint openly (Hebinck, Vervoort, Hebinck, Rutting, \& Galli, 2018). The management of group dynamics, especially across disciplines, cultures and languages must therefore acknowledge power differentials and the pluralities associated with cultural contexts (Marshall, Dolley, \& Priya, 2018). A core aspect of the approach was to ensure co-production of knowledge through approaches such as employing a cultural guide to help with workshop planning, taking time to establish ground rules with local facilitators, a strong focus on creating a sense of community and mutual respect among the participants in the process, employing techniques such as Chatham House Rules, and negotiating the confidentiality of data. These methods support trust building and represent an investment in social capital, which is needed to progress any collective effort.

\section{DISCUSSION}

The ultimate aim of the Nature Futures endeavour is to develop a process for creating multiscale scenarios of desirable futures for nature, which have been legitimized through a co-production process that includes a plurality of perspectives. The IPBES expert group embarked on an iterative process that resulted in the development of the NFF as a tool for engaging a pluralistic set of positive perspectives on human-nature relationships and as a framework for constructing multiscale scenarios. The NFF serves as a boundary object that provides a platform for practitioners, natural and social scientists, policymakers and modellers to reflect on and compare which types of values and which types of relationships with nature are being analysed, discussed and compared. We believe that the use of the NFF within the overall framework enables more nuanced and relevant dialogue around what possible futures for nature can be created. It also forms a foundational framework from which further scenario work can be undertaken. This is discussed more in Section 4.3.

As such, we argue that the contribution of the NFF is twofold:

1. Its ability to hold a plurality of perspectives on what is desirable which enables the development of joint goals and visions and recognizes the possible convergence and synergies of measures to achieve these.
2. Its multiscale functionality for elaborating scenarios and models that can inform decision-making at relevant levels, making it applicable across specific places and knowledge systems.

\section{1 | Holding a plurality of values and perspectives on desirable futures}

\subsection{1 | Desirable futures}

The world needs desirable visions, including targets to stimulate action towards achieving them, as illustrated by the normative power of the SDGs and the well-below $2^{\circ} \mathrm{C}$ target of the Paris Agreement (UNEP, 2019). However, discussions on such desirable futures around biodiversity and particularly the post-2020 agenda in the CBD have tended to accentuate the perceived conflict between diverse perspectives of what a desirable future for nature looks like, problematizing the diversity of underlying values of the human-nature relationship. Many players in the science-policy arena actively lobby for implementation of alternative ideas, but often these ideas do not align, especially when they are popularized and differences are emphasized, which can result in tensions that potentially undermine a collective effort. A clear example is the land-sparing (high-yielding agriculture with a small land footprint) versus land-sharing (low-yielding, wildlife-friendly agriculture on larger tracts of land) debate that offers two alternative pathways for agricultural and urban development to enable better outcomes for local and global biodiversity (Kremen, 2015; Loconto, Desquilbet, Moreau, Couvet, \& Dorin, 2018). The concept of 'Half-Earth' introduced by the naturalist E.O. Wilson has gained significant traction (Büscher et al., 2017; Kopnina, Washington, Gray, \& Taylor, 2018; Wilson, 2016), while other groups advocate for $30 \%$ of the ocean to be protected (Dinerstein et al., 2019). An altogether different solution is found in green growth for sustainable development, celebrating natural capital accounting, naturebased solutions and payment for ecosystem services schemes (Bull \& Strange, 2018; Mandle, Ouyang, Salzman, \& Daily, 2019; Russi $\&$ ten Brink, 2013; TEEB, 2010, 2018). Other research articulates the need for a look at alternative economic models for a flourishing nature (D'Alessandro, Cieplinski, Distefano, \& Dittmer, 2020; Otero et al., 2020).

There is a diversity of perspectives in the global conservation community on how to conserve nature (Mace, 2014; Sandbrook, Fisher, Holmes, Luque-Lora, \& Keane, 2019). Mace (2014) proposed four stages in the evolution of the nature conservation paradigm, from 'nature for itself' to 'nature despite people' to the 'nature for people' approach embodied in the Millennium Ecosystem Assessment (2005). A fourth stage posits that a more nuanced 'nature and people' approach has recently been taken up that recognizes the dynamic relationship between people and nature. These different framings have implications for environmental management and have led to some tensions in the conservation community 
(Sandbrook et al., 2019). Sandbrook et al. (2019) argue that future debates and policy processes should emphasize working through the more contentious issues, and ensure inclusion of the perspectives of under-represented groups in conservation who may not share the views of those in more powerful positions. To this end, the NFF as a heuristic device that has been developed in an interdisciplinary process with widespread stakeholder engagement, can potentially facilitate constructive dialogue to identify and focus on shared ambitions for collective action. By focusing on the positive relationships (i.e. not emphasizing the 'nature despite people' perspective, but including it in the nature for itself value), the NFF work can help to identify and bridge dominant perspectives in the world of nature conservation.

\subsection{2 | Value pluralism}

The embracing of value pluralism makes it possible to fit the NFF to different contexts and identify different behavioural changes associated with particular political, legal and socio-cultural perspectives. By enabling the identification of more diverse types of policy responses and actions that can restore the living world and focusing on the variation among people's relationships to nature, the NFF highlights that acknowledging people's diverse relationships with nature is essential for discussing nature futures and coming to an agreement on ways to achieve a more desirable future. Often, assessments of nature focus on natural sciences or economics and do not consider why and how people care about nature (IPBES, 2019; Millennium Ecosystem Assessment, 2005; UNEP, 2019). In contrast, the NFF approach focuses on reciprocal relationships between people and nature (within the whole of the triangle space) rather than only people's impact on nature, or nature's impact on people. It emphasizes the importance of a pluralistic notion of values compared with monistic approaches to human-nature relationships dominated by a single worldview (that might overemphasize only one target, such as the conservation of biodiversity, economic growth, social development or poverty alleviation, the inclusion of indigenous knowledge) as discussed in the IPBES conceptual framework (Díaz et al., 2015; IPBES Plenary, 2016; Pascual et al., 2017).

The IPBES values framework, referring to intrinsic, instrumental and relational values for nature that are captured in the NFF, and builds on an ongoing scholarship that engages with the need for a diversified framing on values of nature (Chan et al., 2016; Chan, Gould, \& Pascual, 2018; Chan, Satterfield, \& Goldstein, 2012; O'Connor \& Kenter, 2019; Piccolo, 2017). Chan et al. (2016) build on the IPBES guidance and emphasize the importance of the relational values approach, arguing that recognizing these values is critical to the genuine inclusion of diverse groups in environmental stewardship. Piccolo (2017) has added to this debate by arguing that depicting intrinsic values as part of a dichotomy between anthropocentric and ecocentric values is unhelpful and that any attempt to reframe the discussion about values and environmental protection through more formal recognition of relational values will need to more clearly address how relational and intrinsic values coexist. Together with colleagues, he goes on to call for ecocentric values to be a core aspect of the transformation of human's relationship with nature and argues that conservation used to be at the forefront of this approach (Piccolo, Washington, Kopnina, \& Taylor, 2018). Extending the discussion of intrinsic values of nature, O'Connor and Kenter (2019) use the life framework for values to make the case for integrating the more-than-human components of intrinsic values that goes beyond classifications of ecosystem services and NCP.

While the NFF builds on the relational, instrumental and intrinsic values, the three perspectives do not map unequivocally to these values and allow for their coexistence, addressing some of the criticisms of Piccolo (2017). Nature for nature represents both intrinsic values and instrumental values such as existence values and non-material benefits from nature. Nature for society is dominated by the use and indirect use of a subset of instrumental values, while nature as culture captures the relational values, but also the non-material benefits associated with cultural construction and interpretation of nature. The NFF approach is being developed to support scenarios and therefore is closer to stakeholder perspectives than conceptual classifications of the types of nature values. In addition, it recognizes that most stakeholders will find themselves in intermediate positions of the preference space, where all values and perspectives coexist.

\subsection{3 | NFF as a boundary object}

Reinforcing the call by Tadaki, Sinner, and Chan (2017) to move away from theoretical gridlock within the environmental values debate and into a space where the valuation of diverse values of nature can be means of citizen empowerment, the methodological approach of the NFF is an attempt to create a boundary object for bringing different disciplinary perspectives and worldviews together. The creation of a boundary object in the scientific process can be a useful strategy for reconciling tensions between different viewpoints and translating between them so that progress can be made (Star \& Griesemer, 1989). As such, boundary objects must be both adaptable to different viewpoints whilst also being robust enough to maintain identity across them (Star \& Griesemer, 1989). In the biodiversity conservation context, boundary objects have proved to be important tools for navigating different scalar perspectives for improved decision-making (Gray, Gruby, \& Campbell, 2014). The IPBES Conceptual framework itself has been described as a boundary object for opening up the science-policy interface for broader engagement with plural ontologies and epistemologies (Borie \& Hulme, 2015; Scarano et al., 2019). Based on the stakeholder engagements described in Section 3.3, we argue that the NFF triangle has turned out to be useful as a boundary object for bridging multiple disciplines and stakeholder perspectives. As the final outputs of the Nature Futures process must be relevant for a wide audience, including the modelling community, having a common conceptual lynchpin in the NFF has been critical for creating buy-in and understanding across different groups. 
The aim of the NFF is not to replace the frameworks described above, but to provide a heuristic that can hold these different conceptualizations in order to provide a simple, but effective, tool for the creation of multiscale, plural biodiversity scenarios. As such, it is intended to be used as a heuristic device for holding ongoing engagements between diverse perspectives. As intergovernmental assessment processes have a strong influence on how the spatial dimensions of environmental problems are designated and thus how power relations are accordingly reconfigured across different scales and levels (Beck, Esguerra, \& Goerg, 2017), a tool through which to unpack these relations and empower different spatial scales can be an important offering. By capturing diversity in an accessible heuristic, the NFF has the potential to support IPBES assessment work by operationalizing the platform's principles: promoting a collaborative approach; facilitating an interdisciplinary and multidisciplinary approach; engaging with different knowledge systems, including indigenous and local knowledge; and ensuring full, effective balanced participation across national, sub-regional and regional levels. The NFF approach also complements ongoing IPBES work, especially that of the Values Assessment which will be considered by the 9th session of the IPBES Plenary in 2022. Future assessments, including those on transformative change, the nexus of biodiversity, water, food and health and business and biodiversity, will be able to utilize the NFF as an overarching framework around which to organize the analysis of scenarios and models that deal with these topics.

\section{2 | Multiscale functionality to inform decision- making at relevant levels}

Although a growing body of literature has identified the challenges and possibilities associated with developing cross-scale scenarios (Biggs et al., 2007; Kok, Biggs, \& Zurek, 2007; MasonD'Croz et al., 2016; Mistry et al., 2014; Palazzo et al., 2017; Zurek \& Henrichs, 2007), it has mostly focused on rescaling global scenarios for regional and local use using various algorithms (Häyhä, Lucas, van Vuuren, Cornell, \& Hoff, 2016; Kok, Pedde, Gramberger, Harrison, \& Holman, 2019; Kok et al., 2016; Mason-D'Croz et al., 2016; Palazzo et al., 2017). Effective multiscale, and particularly cross-scale analysis is difficult, and it is not only a challenge of scenario planning. Disciplinary research often re-emphasizes the problems of scale: ecologists and social scientists traditionally frame their research questions at different scales and consider different facets of natural resource management, setting different objectives and using different language (Montana \& Borie, 2016; Stevens, Fraser, Mitchley, \& Thomas, 2007), which makes it difficult to connect scales. Within disciplines, scale remains a problem, due to the scale bound nature of research problems and data collection (Levin, 1992).

The NFF has been explicitly designed by an interdisciplinary group of researchers to be used across multiple scales, potentially, but not necessarily, combining scales in the same framework within a cross-scale approach. Overcoming philosophical and disciplinary challenges and embracing the plurality of knowledge systems that lies at the heart of IPBES, were central goals of the expert group as they developed the NFF. Bridging interdisciplinary barriers is required to be able to incorporate more diverse knowledge systems into environmental assessments (Obermeister, 2017). Although not perfect, the group made a lot of effort to embrace a diversity of knowledges, methods, research and discussion styles and this resulted in the NFF triangle operating as a boundary object that can work not only across disciplines, but also across scales.

It is important to point out that packaging and providing knowledge for policy is not a neutral activity, especially when navigating across scales of relevance that requires translating the global environmental knowledge of assessments into a form that is usable by decision-makers that operate at a different level, usually that of a nation state (Turnhout, Dewulf, \& Hulme, 2016). The NFF is not a neutral object that was developed with buy-in from the whole world, and this must be fully acknowledged. A key rationale for the development of this paper is for the NFF development process, with all its associated challenges, to be transparently laid out for all to be able to engage with the process, critique it and improve on it in future iterations. Such epistemological agility is necessary when co-producing knowledge with diverse peoples across different scales (Haider et al., 2017), as highlighted by the work on the multiple evidence base that conceptually informs the NFF as a tool to feed into intergovernmental processes like IPBES and the CBD (Tengö et al., 2017). Finally, the flexibility of the NFF to work across multiple different contexts and with a variety of stakeholders requires it to be relatively simple and this means that it can lose a lot of the nuance and subtlety that is sometimes of great importance when engaging diverse perspectives. This is a core constraint of the NFF, however, its work as a boundary object can alleviate some of this simplification.

\subsection{Next steps in the Nature futures scenarios process}

In order to broaden the engagement with the NFF and to get wide buy-in to its adoption as an actionable framework by diverse researchers, it is imperative that future steps in the process seek actively to involve more people and expertise. The next steps in the scenario development process are to extend the use of the NFF in multilevel case studies to test its relevance across diverse ecosystems, bio-cultural regions and geographical scales. This will involve both the development of new scenarios based on the framework (discussed in Section 4.3.1) as well as the analysis of existing scenarios within the NFF framework. The articulation of variables and indicators that can be quantified by the biodiversity modelling community is also needed. It is hoped that the insights from the case studies will be input for further refinement of the global scenarios, as well as for developing more diverse sets of indicators to assess the progress towards the goals for nature that incorporate more diverse value perspectives (IPBES/7/INF/112 ${ }^{2}$ ).

To be most effective, the development of the multiscale scenarios needs to be coordinated across work that is underway 
elsewhere. Linking to ongoing work on global scenarios connected to the IPCC and UNEP's Global Environment Outlook and Global Biodiversity Outlook, as well as to business and government scenarios, and to the increasing number of local, national and regional social-ecological scenarios, is crucial to gain traction in the user community. This requires strategic planning and innovative communication platforms that engage busy people across a range of interests and scales. Such work can help to catalyse greater societal support for enhanced conservation of nature, but it requires an ongoing commitment of resources, particularly in terms of time and funding. As such, we set out the following two key processes in which we invite interested research and practitioner communities to help take part in furthering.

\subsection{1 | Multi-level case studies}

To better represent the global diversity of values, ecosystems and local contexts, a broader engagement is needed with a wider range of stakeholders situated in different contexts, and including groups such as indigenous peoples, the youth and the private sector. These engagements could be undertaken with support from several IPBES task forces, including the capacity-building task force that has already organized a youth engagement around the NFF and futuring processes (IPBES Capacity Building, 2019) as well as the indigenous and local knowledge task force that convenes dialogues with indigenous peoples and local communities for ongoing IPBES assessments. Mobilizing the research community to use the NFF in their own work is critically important to provide a richness of different case examples. Innovations in research methods can also allow a large group of people from around the world to engage with the scenario process by using online methods that allow many people to contribute their perspectives and narratives. For example, SenseMaker ${ }^{\circledR}$ uses an online application to capture a variety of perspectives and narratives (Van der Merwe et al., 2019). These are just some of the options that we encourage the research community to undertake with us in moving forward the nature futures agenda.

The aim of having a set of case studies is to populate the triangle with examples of how nature values are represented in different locations, across different spatial scales and how these could change into the future (Figure 7). For example, people's relations to nature will vary between the residents of the city of Singapore, Siberian reindeer herders and communities in the south of France. For clarity, it is important to demonstrate that there are two different ways of using the NFF triangle to visualize nature futures in case studies. The first is by identifying a position within the NFF triangle space that represents the relative emphasis of the three value perspectives. The second is represented in Figure 7, where the desired state of the system is represented by a space connecting three points along each of the triangle's vertices, indicating how well that particular value perspective is achieved. This approach is more appropriate for a bottom-up approach to global scenario narratives as it is easier to amalgamate the desired state space rather than a point within the triangle.

The goal of such efforts is to identify key variables and indicators for different nature perspectives that can help the community operationalize this framework in a way that is both globally comparable and locally relevant, as well as identify commonalities and differences among desired visions of nature around the world. Comparison of such case studies can also be used to identify shared drivers, and ignored or hidden teleconnections between local places (Martín-López et al., 2019). This type of comparison is necessary to
FIGURE 7 Local NFF case studies that engage a variety of actors in different social, geographic and ecological contexts are vital for understanding how global change varies from place to place, the diversity of nature values and how local places connect to global processes. When scaled to the global level, the richness of this bottom-up information can be combined to showcase a diversity of options of what desirable futures for nature could look like globally, based on different emphasis on the nature value perspectives. The use of the NFF enables an opening up of the value perspective space when describing possible nature futures as compared to the present state. (Source: Authors' own)

\section{Different NFF case studies from around the world}

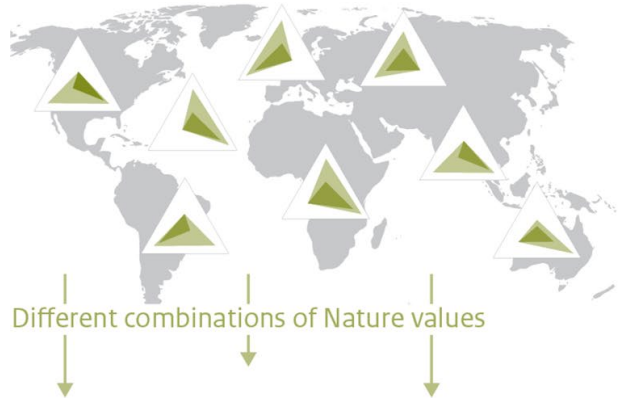

Illustrative, bottom-up global NFF scenarios

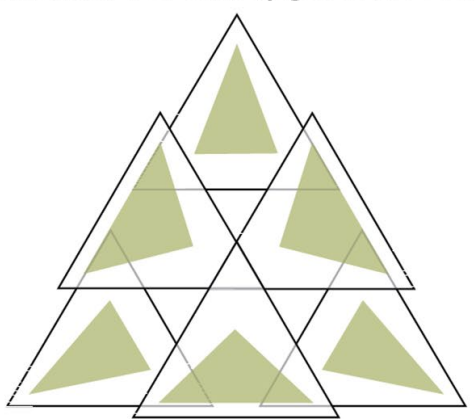

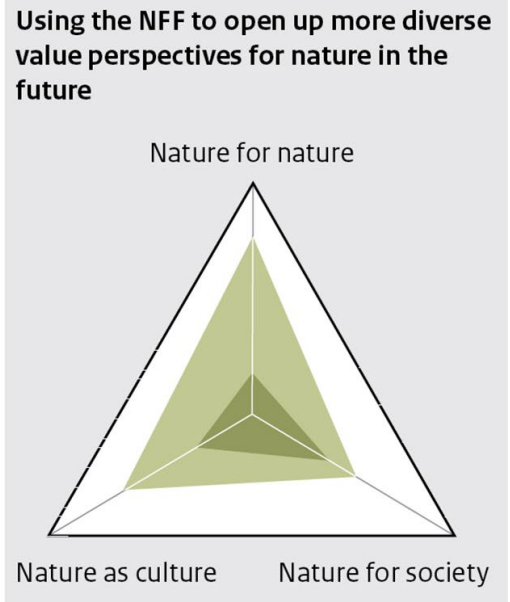

Using the NFF to open up more diverse future

$\triangle$ NFF triangle

A Present combination of Nature values Futures combination of Nature values 
ensure that global analyses adequately identify the cross-scale dynamics that are shaping the world.

Having the NFF as a clear common framework linking these case studies will be important for consistency, especially for providing inputs for the modelling community. We therefore encourage those who are interested in applying the NFF in their context to undertake scenario processes using the NFF as a foundation to ensure consistency and comparability of the findings. Existing examples include a youth workshop organized in Brazil by the IPBES task force on capacity building as well as a case study in the National Park Hollandse Duinen in The Netherlands. More substantial guidelines on how to get involved are also being developed.

As with all participatory visioning and scenarios processes, issues of power, politics and representation, come to the fore (Hebinck et al., 2018; Oteros-Rozas et al., 2015; Pereira et al., 2018). Recognizing inherent biases whilst trying to foster a wide range of perspectives is also a methodological challenge (Schirrmeister, Göhring, \& Warnke, 2020). Navigating these dynamics in a global, participatory process is particularly challenging as it will never be fully representative of the whole world. Furthermore, in asking for the research and practitioner communities to undertake case studies, there is no systematic plan for ensuring representativeness. However, we hope that by encouraging the involvement of the wider community, by leveraging the diversity of stakeholders in the IPBES process and by actively targeting our own research to ensure the views of under-represented groups such as indigenous knowledge holders, are included, that this process will be a significant step towards a new set of globally relevant, but locally applicable desirable nature scenarios.

\subsection{2 | The application of the NFF for the modelling community}

Given the complexity of dynamic social-ecological systems, which encompass interconnected natural and human systems that are multi-dimensional with countless feedbacks within and between systems, integrative modelling of environmental scenarios has been a challenge (Pereira et al., 2010; Rosa et al., 2017). In Nature Futures modelling, connecting the visions to the ongoing and emerging work of modelling groups will require substantial investment in modelling capacity and capability associated with participatory modelling, social-ecological feedback modelling, cross scale modelling and understanding leverage points for transformative change (Leclere et al., 2018). The application of the NFF requires a modelling capability for assessing interlinked impacts of dynamic nature on societies as well as transformative change processes, with better integration of the feedbacks within linked human-environment systems.

A considerable number of indicators have been selected for use in IPBES regional and global assessments as documented by the IPBES task force on knowledge and data. ${ }^{3}$ However, there are substantial gaps in modelling elements and indicators for socio-economic elements and human well-being, and few available indicators that are relevant to the Nature as Culture value perspective (Mastrángelo et al., 2019; PBL, 2018). In particular, having reviewed the findings of the IPBES regional and thematic assessments, Mastrángelo et al. (2019) emphasized that a limited understanding remains of the role that indigenous and local knowledge plays in sustaining the co-production of NCP. Other gaps include the relationships between multiple dimensions of NCP and good quality of life, the temporal dynamics of nonlinear social and ecological change, social-ecological feedbacks including how changes in people's preferences and quality of life influence governance and other indirect drivers, trade-offs between NCP, the influence of institutions in the social distribution of NCP and the effectiveness of governance systems to promote necessary transformations (Mastrángelo et al., 2019). Filling these gaps requires knowledge sharing across disciplines (e.g. modelling, natural and social science, ILK). We encourage the modelling community as well as all other researchers interested in furthering this component to engage with us in developing this body of work.

\section{5 | CONCLUSION: REFRAMING NATURE FUTURES}

As the IPBES Global Assessment (2019) has shown that Nature is declining globally at rates unprecedented in human history and makes it clear that transformative changes are needed to get us onto a more sustainable trajectory for the planet. Under the current socioeconomic trajectory, the world will miss most of the Sustainable Development Goals (SDGs), and so we need to initiate changes in our economies, technologies and societies if we are to shift onto a more sustainable global development pathway (Naidoo \& Fisher, 2020). The development of the NFF rests on the assumption that there is a critical need to develop positive nature-people scenarios for the future of our planet, particularly at such a moment when we need to act now to prevent irreversible environmental devastation with severe consequences to humanity (Steffen et al., 2018; Wyborn et al., 2020).

The year 2019 saw a diversity of perspectives on how to address the environmental challenges of our time. Examples include Extinction Rebellion ${ }^{4}$ that argues that the global environmental crisis is an emergency marked by abrupt climate breakdown and mass extinctions and a global youth movement to avert a climate disaster, sparked by teenager Greta Thunberg, which resulted in mass climate protests and climate strikes by children around the world, referencing \#FridaysfortheFuture ${ }^{5}$ (Almeida, 2019). The World Economic Forum is advocating for a New Deal for Nature (Lambertini, Polman, \& Børge, 2019), and the Global Deal for Nature has been proposed by the biodiversity research community (Dinerstein et al., 2019). Politicians are forming alliances with researchers and activists to propose interventions like The Green New Deal ${ }^{6}$ led by United States Representative Alexandria 
Ocasio-Cortez and Senator Ed Markey. In the context of such diversity, the NFF allows for a standardized approach to appreciate a plurality of NCP over time and space and allows for a more nuanced approach to pathways development that is more relevant for actors operating within specific jurisdictions. Given the need for negotiating a new deal for nature in the post-2020 CBD agenda (Dinerstein et al., 2019; Lambertini et al., 2019), the NFF could create a space wherein a discussion on reversing the degradation of nature and declines in NCP could be held between actors as diverse as politicians and young climate activists.

All the necessary groundwork is currently being laid for the negotiations at CBD COP-15 on the post-2020 biodiversity framework and the global goals on nature to replace the Aichi biodiversity targets. As we navigate the next chapter in global biodiversity governance, the NFF makes a unique contribution towards improving the sciencepolicy interface that can enable a better future for people and nature. However, this cannot be an isolated endeavour. We call on the research community to join us in testing and improving the framework in diverse contexts and where appropriate to use it in their work. In this way, together we can move towards a more desirable and hopeful future for people and the planet.

\section{ACKNOWLEDGEMENTS}

The authors would firstly like to acknowledge and thank all the workshop and survey participants for their time and contribution in the development of this framework and paper. The process leading to the NFF was partially funded by funds from the Intergovernmental SciencePolicy Platform on Biodiversity and Ecosystem Services with support from the technical support unit (TSU) on scenarios and models, hosted and co-funded by PBL Netherlands Environmental Assessment Agency. Funding to support travel and participation in the IPBES Nature Futures workshop was provided by the New Zealand Ministry for Business, Innovation and Employment (MBIE) Catalyst: Seeding fund administered by the Royal Society of New Zealand (contract \#CSG-NIW1701), the IPBES trust fund, the Dutch Ministry of Economic Affairs, the Dutch Ministry of Foreign Affairs, the New Zealand National Institute of Water \& Atmospheric Research (NIWA), the University of Auckland School of Science, the Centre for Biodiversity and Biosecurity (Manaaki Whenua - Landcare Research/University of Auckland), Fullers and 360 Discovery Cruises. Additional workshop contributions were provided by Lou Sanson (Director-General, Department of Conservation), John Quinn (NIWA), John Hosking and Michael Steedman (University of Auckland) and the Auckland University Pacific Island Students Association. Participation in the Rio Conventions Pavilion CBD COP 14 has been funded by PBL Netherlands Environmental Assessment Agency, the Dutch Ministry of Agriculture, Nature and Food Quality and NIWA. We would also like to acknowledge contributions from the Nippon Foundation's Nereus Program on Predicting Future Oceans as well as the Peter Wall Institute for Advanced Studies and the Changing Ocean Research Unit (CORU) at the University of British Columbia for hosting the March 2019 meeting of the expert group. We thank Sandy van Tol from PBL for the graphic design of the figures and to Mary Brake, Reflection Graphics; Dave Leigh, Emphasise
Ltd.; Pepper Lindgren-Streicher, Pepper Curry Design for the images from the Auckland workshop. A special thank you to those who helped with translation of the summary and abstract: Alina Peele, Bauke Kuiper, Chimère Diaw, Chris Vrettos, Dandan Yu, Felicia Senya, Garikai Nyaruwata, Ghassen Halouani, Grace Mwaura, Jean-Baptiste Jouffray, Juliano Palacios-Abrantes, Leonorah Nyaruwata, Märta Jacobson, Mulenga Kapwepwe, Musonda Mumba, Maureen Bosch, Niketi Toataua, Olayinka A. Oridupa, Onthatile Peele, Philile Mbatha, Sakshi Rana, Shepard Nyaruwata, Shizuka Hashimoto, Sumana Hussain, Tshiamo Marogoa, Tumisang Peele and Zeph Makgetla. Finally, we would like to acknowledge the extremely useful input from anonymous reviewers and journal editors that was essential in strengthening the manuscript. This work is based on the research supported in part by the National Research Foundation of South Africa (Grant Numbers 115300) and the Swedish Research Council (FORMAS Project No. 2018-02371).

\section{CONFLICT OF INTEREST}

The authors have no conflict of interest with regard to the publication of this manuscript.

\section{AUTHORS' CONTRIBUTIONS}

For the Auckland workshop, L.M.P., C.J.L., H.M.P. and G.P. conceived the ideas and designed methodology; C.J.L., R.A. and H.M.P. acquired funding; L.M.P., G.P., H.M.P., K.K.D., C.J.L., F.R., S.K.-V., R.A., N.K., S.C.R., J.H., E.d.B., T.L., A.G., facilitated the Auckland workshop; S.O., M.S., E.d.B., H.K., C.J.L. and J.J.K. collected and analysed the data from the workshop and subsequent stakeholder consultations and expert group meetings; L.M.P. led the writing of the manuscript. All authors contributed critically to the drafts and gave final approval for publication.

\section{DATA AVAILABILITY STATEMENT}

All data are available in the cited reports and in Tables S1, S2 and S3 (source: Lundquist et al., 2017).

\section{ORCID}

Laura M. Pereira iD https://orcid.org/0000-0002-4996-7234 Jan J. Kuiper (iD https://orcid.org/0000-0002-6655-9355 Henrique M. Pereira (iD https://orcid.org/0000-0003-1043-1675 Machteld Schoolenberg iD https://orcid. org/0000-0002-8940-0291

Rob Alkemade iD https://orcid.org/0000-0001-8761-1768

Nicholas King (iD https://orcid.org/0000-0002-9624-1356 Jean-Paul Metzger iD https://orcid.org/0000-0002-0087-5240

\section{ENDNOTES}

1 https://ipbes.net/diverse-values-valuation

2 https://ipbes.net/sites/default/files/ipbes-7-inf-11_scenarios.pdf

${ }^{3}$ https://ipbes.net/core-indicators

4 https://rebellion.earth/

${ }^{5}$ https://www.fridaysforfuture.org/

6 https://theintercept.com/2019/04/17/green-new-deal-short-film-alexandria-ocasio-cortez/ 


\section{REFERENCES}

Almeida, P. (2019). Climate justice and sustained transnational mobilization. Globalizations, 16(7), 973-979. https://doi.org/10.1080/14747 731.2019 .1651518

Armitage, D., Dzyundzyak, A., Baird, J., Bodin, Ö., Plummer, R., \& Schultz, L. (2018). An approach to assess learning conditions, effects and outcomes in environmental governance. Environmental Policy and Governance, 28(1), 3-14. https://doi.org/10.1002/eet.1781

Ayyub, B. M. (2001). Elicitation of expert opinions for uncertainty and risks (1st ed.). Boca Raton, FL: CRC Press.

Balvanera, P., Pascual, U., Diaz, S., Dziba, L., Richard, A.-H.-P., \& Subramanian, S. M. (2017). Urgent need to strengthen the international commitment to IPBES. Nature Ecology \& Evolution, 1(1), 0197. https://doi.org/10.1038/s41559-017-0197

Beck, S., Esguerra, A., \& Goerg, C. (2017). The co-production of scale and power: The case of the millennium ecosystem assessment and the intergovernmental platform on biodiversity and ecosystem services. Journal of Environmental Policy and Planning, 19(5), 534-549.

Bennett, E. M., Solan, M., Biggs, R., McPhearson, T., Norström, A. V., Olsson, P., ... Xu, J. (2016). Bright spots: Seeds of a good Anthropocene. Frontiers in Ecology and the Environment, 14(8), 441-448. https://doi. org/10.1002/fee.1309

Biggs, R., Raudsepp-Hearne, C., Atkinson-Palombo, C., Bohensky, E., Boyd, E., Cundill, G., ... Zurek, M. (2007). Linking futures across scales: A dialogue on multiscale scenarios. Ecology and Society, 12(1), 17.

Borie, M., \& Hulme, M. (2015). Framing global biodiversity: IPBES between mother earth and ecosystem services. Environmental Science and Policy, 54, 487-496. https://doi.org/10.1016/j. envsci.2015.05.009

Bull, J. W., \& Strange, N. (2018). The global extent of biodiversity offset implementation under no net loss policies. Nature Sustainability, 1(12), 790-798. https://doi.org/10.1038/s41893-018-0176-z

Büscher, B., Fletcher, R., Brockington, D., Sandbrook, C., Adams, W. M., Campbell, L., ... Shanker, K. (2017). Half-earth or whole earth? Radical ideas for conservation, and their implications. Oryx, 51(3), 407-410. https://doi.org/10.1017/S0030605316001228

Cairns, G., \& Wright, G. (2019). Making scenario interventions matter: Exploring issues of power and rationality. Futures \& Foresight Science, 1(1), e10. https://doi.org/10.1002/ffo2.10

Chan, K. M. A., Balvanera, P., Benessaiah, K., Chapman, M., Díaz, S., Gómez-Baggethun, E., ... Turner, N. (2016). Opinion: Why protect nature? Rethinking values and the environment. Proceedings of the National Academy of Sciences, 113(6), 1462-1465. https://doi. org/10.1073/pnas.1525002113

Chan, K. M., Gould, R. K., \& Pascual, U. (2018). Editorial overview: Relational values: What are they, and what's the fuss about? Current Opinion in Environmental Sustainability, 35, A1-A7. https://doi. org/10.1016/j.cosust.2018.11.003

Chan, K. M. A., Satterfield, T., \& Goldstein, J. (2012). Rethinking ecosystem services to better address and navigate cultural values. Ecological Economics, 74, 8-18. https://doi.org/10.1016/j.ecolecon. 2011.11.011

Clemen, R. T., \& Winkler, R. L. (1999). Combining probability distributions from experts in risk analysis. Risk Analysis, 19(2), 187-203. https:// doi.org/10.1111/j.1539-6924.1999.tb00399.x

Coker, J., Castiglioni, A., Kraemer, R. R., Massie, F. S., Morris, J. L., Rodriguez, M., ... Estrada, C. A. (2014). Evaluation of an advanced physical diagnosis course using consumer preferences methods: The nominal group technique. American Journal of the Medical Sciences, 347(3), 199-205. https://doi.org/10.1097/MAJ.0b013 e3182831798

Cumming, G. S., Alcamo, J., Sala, O., Swart, R., Bennett, E. M., \& Zurek, M. (2005). Are existing global scenarios consistent with ecological feedbacks? Ecosystems, 8(2), 143-152. https://doi.org/10.1007/ s10021-004-0075-1

Curry, A., \& Hodgson, A. (2008). Seeing in multiple horizons: Connecting futures to strategy. Journal of Futures Studies, 13(1), 1-20.

D'Alessandro, S., Cieplinski, A., Distefano, T., \& Dittmer, K. (2020). Feasible alternatives to green growth. Nature Sustainability, 3(4), 329-335. https://doi.org/10.1038/s41893-020-0484-y

Dalkey, N., \& Helmer, O. (1963). An exmperimental application of the Delphi method to the use of experts. Management Science, 9 458-467.

Díaz, S., Demissew, S., Carabias, J., Joly, C., Lonsdale, M., Ash, N., ... Zlatanova, D. (2015). The IPBES conceptual framework-Connecting nature and people. Current Opinion in Environmental Sustainability, 14 1-16. https://doi.org/10.1016/j.cosust.2014.11.002

Dinerstein, E., Vynne, C., Sala, E., Joshi, A. R., Fernando, S., Lovejoy, T. E., ... Wikramanayake, E. (2019). A global deal for nature: Guiding principles, milestones, and targets. Science Advances, 5(4), eaaw2869. https://doi.org/10.1126/sciadv.aaw2869

Duncan, R. (2004). Nominal group technique: A user's manual. Madison, WI: University of Wisconsin

Duncan, R., Robson-Williams, M., Nicholas, G., Turner, J., Smith, R., \& Diprose, D. (2018). Transformation is 'experienced, not delivered': Insights from grounding the discourse in practice to inform policy and theory. Sustainability, 10(9), 3177. https://doi.org/10.3390/ su10093177

Dunn, G., \& Laing, M. (2017). Policy-makers perspectives on credibility, relevance and legitimacy (CRELE). Environmental Science \& Policy, 76, 146-152. https://doi.org/10.1016/j.envsci.2017.07.005

Ferguson, B. C., Frantzeskaki, N., \& Brown, R. R. (2013). A strategic program for transitioning to a water sensitive city. Landscape and Urban Planning, 117, 32-45. https://doi.org/10.1016/j.landu rbplan.2013.04.016

Ferrier, S., Ninan, K. N., Leadley, P., Alkemade, R., Acosta, L. A., Akçakaya, H. R., ... Wintle, B. (2016). The methodological assessment report on scenarios and models of biodiversity and ecosystem services. Bonn, Germany: IPBES.

Frantzeskaki, N., Loorbach, D., \& Meadowcroft, J. (2012). Governing transitions to sustainability: Transition management as a governance approach towards pursuing sustainability. International Journal of Sustainable Development, 15(January), 1-18.

Glenn, J. C. (2009). The futures wheel. In J. C. Glenn \& T. J. Gordon (Eds.), Futures research methodology (pp. 1-17). Washington, DC: Millennium Project.

Gray, N. J., Gruby, R. L., \& Campbell, L. M. (2014). Boundary objects and global consensus: Scalar narratives of marine conservation in the convention on biological diversity. Global Environmental Politics, 14(3), 64-83. https://doi.org/10.1162/GLEP_a_00239

Haider, L. J., Hentati-Sundberg, J., Giusti, M., Goodness, J., Hamann, M., Masterson, V. A., ... Sinare, H. (2017). The undisciplinary journey: Early-career perspectives in sustainability science. Sustainability Science, 13(1), 191-204. https://doi.org/10.1007/s1162 5-017-0445-1

Hannagan, R. J., \& Larimer, C. W. (2010). Does gender composition affect group decision outcomes? Evidence from a laboratory experiment. Political Behavior, 32(1), 51-67. https://doi.org/10.1007/s1110 9-009-9087-z

Harrison, P. A., Hauck, J., Austrheim, G., Brotons, L., Cantele, M., Claudet, J., ... Turok, J. (2018). Chapter 5: Current and future interactions between nature and society. In M. Rounsevell, M. Fischer, A. TorreMarin Rando, \& A. Mader (Eds.), The IPBES regional assessment report on biodiversity and ecosystem services for Europe and Central Asia (pp. 571-658). Bonn, Germany: Secretariat of the Intergovernmental Science-Policy Platform on Biodiversity and Ecosystem Services.

Harvey, N., \& Holmes, C. A. (2012). Nominal group technique: An effective method for obtaining group consensus. International Journal of 
Nursing Practice, 18(2), 188-194. https://doi.org/10.1111/j.1440172X.2012.02017.x

Häyhä, T., Lucas, P. L., van Vuuren, D. P., Cornell, S. E., \& Hoff, H. (2016). From planetary boundaries to national fair shares of the global safe operating space-How can the scales be bridged? Global Environmental Change, 40, 60-72. https://doi.org/10.1016/j.gloenvcha.2016.06.008

Hebinck, A., Vervoort, J. M., Hebinck, P., Rutting, L., \& Galli, F. (2018). Imagining transformative futures: Participatory foresight for food systems change. Ecology and Society, 23(2), 230216. https://doi. org/10.5751/ES-10054-230216

Hoekstra, A. Y., \& Wiedmann, T. O. (2014). Humanity's unsustainable environmental footprint. Science, 344(6188), 1114-1117. https://doi. org/10.1126/science.1248365

IISD. (2018). Rio conventions pavilion at CBD COP 14: Highlights for Tuesday, 20 November 2018. Sharm El Sheik, Egypt: IISD.

IPBES. (2015). Preliminary guide regarding diverse conceptualization of multiple values of nature and its benefits, including biodiversity and ecosystem functions and services (deliverable 3 (d)). Bonn, Germany: IPBES.

IPBES. (2016). The methodological assessment report on scenarios and models of biodiversity and ecosystem services: Summary for policymakers (S. Ferrier, K. N. Ninan, P. Leadley, R. Alkemade, L. A. Acosta, H. R. Akçakaya, L. Brotons, W. Cheung, V. Christensen, K. A. Harhash, J. Kabubo-Mariara, C. Lundquist, M. Obersteiner, H. Pereira, G. Peterson, R. Pichs-Madruga, N. H. Ravindranath, C. Rondinini, \& B. Wintle, Eds.). Bonn, Germany: Intergovernmental Science-Policy Platform on Biodiversity and Ecosystem Services.

IPBES. (2019). The global assessment report on biodiversity and ecosystem services of the intergovernmental science-policy platform on biodiversity and ecosystem services. Bonn, Germany: IPBES.

IPBES Capacity Building. (2019). IPBES youth workshop report. Oslo, Norway: IPBES.

IPBES Plenary. (2016). Work programme of the Platform: Revised scoping report for a methodological assessment on diverse conceptualization of multiple values of nature and its benefits (IPBES/6/15). Kuala Lumpur, Malaysia: IPBES Plenary.

IPCC. (2018). Summary for policymakers. In V. Masson-Delmotte, P. Zhai, H.-O. Pörtner, D. Roberts, J. Skea, P. R. Shukla, A. Pirani, W. MoufoumaOkia, C. Péan, R. Pidcock, S. Connors, J. B. R. Matthews, Y. Chen, X. Zhou, M. I. Gomis, E. Lonnoy, T. Maycock, M. Tignor, \& T. Waterfield (Eds.), An IPCC Special Report on the impacts of global warming of $1.5^{\circ} \mathrm{C}$ above pre-industrial levels and related greenhouse gas emission pathways, in the context of strengthening the global response to the threat of climate change, sustainable development and efforts to eradicate poverty (pp. 132). Geneva, Switzerland: World Meteorological Organization.

Johnson, J. A., Baldos, U., Hertel, T., Liu, J., Nootenboom, C., Polasky, S., \& Roxburgh, T. (2020). Global futures: Modelling the global economic impacts of environmental change to support policy-making. Woking, UK: WWF, GTAP and the Natural Capital Project.

Kok, K., Biggs, R., \& Zurek, M. (2007). Methods for developing multiscale participatory scenarios: Insights from Southern Africa and Europe. Ecology and Society, 12(1), 120108. https://doi.org/10.5751/ES01971-120108

Kok, K., Pedde, S., Gramberger, M., Harrison, P. A., \& Holman, I. P. (2019). New European socio-economic scenarios for climate change research: Operationalising concepts to extend the shared socioeconomic pathways. Regional Environmental Change, 19(3), 643-654. https://doi.org/10.1007/s10113-018-1400-0

Kok, M. T. J., Kok, K., Peterson, G. D., Hill, R., Agard, J., \& Carpenter, S. R. (2016). Biodiversity and ecosystem services require IPBES to take novel approach to scenarios. Sustainability Science, 12(1), 177-181. https://doi.org/10.1007/s11625-016-0354-8

Kopnina, H., Washington, H., Gray, J., \& Taylor, B. (2018). The 'future of conservation' debate: Defending ecocentrism and the Nature Needs Half movement. Biological Conservation, 217, 140-148. https://doi. org/10.1016/j.biocon.2017.10.016.
Korhonen, J., Honkasalo, A., \& Seppälä, J. (2018). Circular economy: The concept and its limitations. Ecological Economics, 143, 37-46. https:// doi.org/10.1016/j.ecolecon.2017.06.041

Kremen, C. (2015). Reframing the land-sparing/land-sharing debate for biodiversity conservation. Annals of the New York Academy of Sciences, 1355(1), 52-76.

Laing, M., \& Wallis, P. J. (2016). Scientists versus policy-makers: Building capacity for productive interactions across boundaries in the urban water sector. Environmental Science and Policy, 66, 23-30. https://doi. org/10.1016/j.envsci.2016.08.001

Lambertini, M., Polman, P., \& Børge, B. (2019). In 2020, we need a new deal for nature. Geneva, Switzerland: World Economic Forum.

Leclere, D., Obersteiner, M., Alkemade, R., Almond, R., Barrett, M., \& Bunting, G. (2018). Towards pathways bending the curve terrestrial biodiversity trends within the 21st century. Laxemburg, Austria: IIASA.

Levin, S. A. (1992). The problem of pattern and scale in ecology: The Robert H. MacArthur award lecture. Ecology, 73(6), 1943-1967. https://doi.org/10.2307/1941447

Loconto, A., Desquilbet, M., Moreau, T., Couvet, D., \& Dorin, B. (2020). The land sparing - land sharing controversy: Tracing the politics of knowledge. Land Use Policy, 96, 103610. https://doi.org/10.1016/ j.landusepol.2018.09.014

Luederitz, C., Abson, D. J., Audet, R., \& Lang, D. J. (2017). Many pathways toward sustainability: Not conflict but co-learning between transition narratives. Sustainability Science, 12(3), 393-407. https://doi. org/10.1007/s11625-016-0414-0

Lundquist, C. J., Pereira, H., Alkemade, R., Den Belder, E., Carvalho Ribeira, S., Davies, K., ... Leigh, D. (2017). Visions for nature and nature's contributions to people for the 21st century, NIWA Science and Technology Series 83 (1-123). Auckland, New Zealand: NIWA.

Mace, G. M. (2014). Whose conservation? Science, 345(6204), 15581560. https://doi.org/10.1126/science.1254704

Mandle, L., Ouyang, Z., Salzman, J., \& Daily, G. C. (2019). Green growth that works: Natural capital policy and finance mechanisms from around the world (L. Mandle, Z. Ouyang, J. Salzman, \& G. C. Daily, Eds.). Washington, DC: Island Press.

Marshall, F., Dolley, J., \& Priya, R. (2018). Transdisciplinary research as transformative space making for sustainability: Enhancing propoor transformative agency in periurban contexts. Ecology and Society, 23(3), 230308. https://doi.org/10.5751/ES-10249-230308

Martín-López, B., Felipe-Lucia, M. R., Bennett, E. M., Norström, A., Peterson, G., Plieninger, T., ... Locatelli, B. (2019). A novel telecoupling framework to assess social relations across spatial scales for ecosystem services research. Journal of Environmental Management, 241, 251-263. https://doi.org/10.1016/j.jenvman.2019.04.029

Mason-D'Croz, D., Vervoort, J., Palazzo, A., Islam, S., Lord, S., Helfgott, A., ... Lipper, L. (2016). Multi-factor, multi-state, multi-model scenarios: Exploring food and climate futures for Southeast Asia. Environmental Modelling \& Software, 83, 255-270. https://doi.org/10.1016/j.envsoft. 2016.05.008

Mastrángelo, M. E., Pérez-Harguindeguy, N., Enrico, L., Bennett, E., Lavorel, S., Cumming, G. S., ... Zoeller, K. (2019). Key knowledge gaps to achieve global sustainability goals. Nature Sustainability, 2(12), 1115-1121. https://doi.org/10.1038/s41893-019-0412-1

Millennium Ecosystem Assessment. (2005). Ecosystems and human well-being: Synthesis. Washington, DC: Island Press.

Mistry, J., Tschirhart, C., Verwer, C., Glastra, R., Davis, O., Jafferally, D., ... Berardi, A. (2014). Our common future? Cross-scalar scenario analysis for social-ecological sustainability of the Guiana Shield, South America. Environmental Science \& Policy, 44, 126-148. https://doi. org/10.1016/j.envsci.2014.05.007

Montana, J., \& Borie, M. (2016). IPBES and biodiversity expertise: Regional, gender, and disciplinary balance in the composition of the interim and 2015 multidisciplinary expert panel. Conservation Letters, 9(2), 138-142. https://doi.org/10.1111/conl.12192 
Naidoo, R., \& Fisher, B. (2020). Reset sustainable development goals for a pandemic world. Nature, 583(7815), 198-201. https://doi. org/10.1038/d41586-020-01999-x

Norström, A. V., Cvitanovic, C., Löf, M. F., West, S., Wyborn, C., Balvanera, P., ... Österblom, H. (2020). Principles for knowledge co-production in sustainability research. Nature Sustainability, 3(3), 182-190. https://doi.org/10.1038/s41893-019-0448-2

Obermeister, N. (2017). From dichotomy to duality: Addressing interdisciplinary epistemological barriers to inclusive knowledge governance in global environmental assessments. Environmental Science and Policy, 68, 80-86. https://doi.org/10.1016/j.envsci.2016.11.010

Obermeister, N. (2019). Local knowledge, global ambitions: IPBES and the advent of multi-scale models and scenarios. Sustainability Science, 14, 843-856.

O'Connor, S., \& Kenter, J. O. (2019). Making intrinsic values work; integrating intrinsic values of the more-than-human world through the life framework of values. Sustainability Science, 14(5), 1247-1265. https://doi.org/10.1007/s11625-019-00715-7

O'Neill, B. C., Kriegler, E., Ebi, K. L., Kemp-Benedict, E., Riahi, K., Rothman, D. S., ... Solecki, W. (2017). The roads ahead: Narratives for shared socioeconomic pathways describing world futures in the 21st century. Global Environmental Change, 42, 169-180. https://doi. org/10.1016/j.gloenvcha.2015.01.004

O'Neill, B. C., Kriegler, E., Riahi, K., Ebi, K. L., Hallegatte, S., Carter, T. R., ... van Vuuren, D. P. (2014). A new scenario framework for climate change research: The concept of shared socioeconomic pathways. Climatic Change, 122(3), 387-400. https://doi.org/10.1007/s10584-013-0905-2

Otero, I., Farrell, K. N., Pueyo, S., Kallis, G., Kehoe, L., Haberl, H., ... Pe'er, G. (2020). Biodiversity policy beyond economic growth. Conservation Letters, 1-18. https://doi.org/10.1111/conl.12713.

Oteros-Rozas, E., Martín-López, B., Daw, T. M., Bohensky, E. L., Butler, J. R. A., Hill, R., ... Vilardy, S. P. (2015). Participatory scenario planning in place-based social-ecological research: Insights and experiences from 23 case studies. Ecology and Society, 20(4), 200432. https://doi. org/10.5751/ES-07985-200432

Palazzo, A., Vervoort, J. M., Mason-D'Croz, D., Rutting, L., Havlík, P., Islam, S., ... Zougmore, R. (2017). Linking regional stakeholder scenarios and shared socioeconomic pathways: Quantified West African food and climate futures in a global context. Global Environmental Change: Human and Policy Dimensions, 45, 227-242. https://doi. org/10.1016/j.gloenvcha.2016.12.002

Pascual, U., Balvanera, P., Díaz, S., Pataki, G., Roth, E., Stenseke, M., ... Yagi, N. (2017). Valuing nature's contributions to people: The IPBES approach. Current Opinion in Environmental Sustainability, 26-27, 716. https://doi.org/10.1016/j.cosust.2016.12.006

PBL. (2018). Next steps in developing nature futures. The Hague, The Netherlands: PBL.

Pereira, H. M., Leadley, P. W., Proença, V., Alkemade, R., Scharlemann, J. P., Fernandez-Manjarrés, J. F., ... Chini, L. (2010). Scenarios for global biodiversity in the 21st century. Science, 330(6010), 1496-1501. https://doi.org/10.1126/science.1196624

Pereira, L., Asrar, G. R., Fisher, L. H., Hsu, A., Nel, J., Sitas, N., ... Zhang, Y. (2019). Bottom-up initiatives and participatory approaches for outlooks. In P. Ekins \& J. Gupta (Eds.), Global Environment Outlook (GEO 6) (pp. 545-578). Cambridge, UK: Cambridge University Press.

Pereira, L., Frantzeskaki, N., Hebinck, A., Charli, L., Scott, J., Dyer, M., ... Vervoort, J. M. (2019). Transformative spaces in the making: Key lessons from nine cases in the Global South. Sustainability Science, 15(1), 161-178. https://doi.org/10.1007/s11625-019-00749-x

Pereira, L. M., Hichert, T., Hamann, M., Preiser, R., \& Biggs, R. (2018). Using futures methods to create transformative spaces: Visions of a good Anthropocene in southern Africa. Ecology and Society, 23(1), 230119. https://doi.org/10.5751/ES-09907-230119

Pereira, L., Sitas, N., Ravera, F., Jimenez-Aceituno, A., \& Merrie, A. (2019). Building capacities for transformative change towards sustainability:
Imagination in intergovernmental science-policy scenario processes. Elementa Science of the Anthropocene, 7(1), 35. https://doi. org/10.1525/elementa.374

Peterson, G. D., Harmáčková, Z. V., Meacham, M., Queiroz, C., JiménezAceituno, A., Kuiper, J. J., ... Bennett, E. M. (2018). Welcoming different perspectives in IPBES: 'Nature's contributions to people' and 'Ecosystem services'. Ecology and Society, 23(1), art39.

Piccolo, J. J. (2017). Intrinsic values in nature: Objective good or simply half of an unhelpful dichotomy? Journal for Nature Conservation, 37, 8-11. https://doi.org/10.1016/j.jnc.2017.02.007

Piccolo, J. J., Washington, H., Kopnina, H., \& Taylor, B. (2018). Why conservation scientists should re-embrace their ecocentric roots. Conservation Biology, 32(4), 959-961. https://doi.org/10.1111/ cobi.13067

Priess, J. A., \& Hauck, J. (2014). Integrative scenario development. Ecology and Society, 19(1), 190112. https://doi.org/10.5751/ES06168-190112

Rankin, N. M., McGregor, D., Butow, P. N., White, K., Phillips, J. L., Young, J. M., ... Shaw, T. (2016). Adapting the nominal group technique for priority setting of evidence-practice gaps in implementation science. BMC Medical Research Methodology, 16(1), 110. https://doi. org/10.1186/s12874-016-0210-7

Rosa, I. M. D., Pereira, H. M., Ferrier, S., Alkemade, R., Acosta, L. A., Akcakaya, H. R., ... van Vuuren, D. (2017). Multiscale scenarios for nature futures. Nature Ecology \& Evolution, 1(10), 1416-1419. https:// doi.org/10.1038/s41559-017-0273-9

Russi, D., \& ten Brink, P. (2013). Natural capital accounting and water quality: Commitments, benefits, needs and progress. A briefing note. Geneva, Switzerland: The Economics of Ecosystems and Biodiversity (TEEB).

Saito, O., Hashimoto, S., Managi, S., Aiba, M., Yamakita, T., DasGupta, R., \& Takeuchi, K. (2019). Future scenarios for socio-ecological production landscape and seascape. Sustainability Science, 14(1), 1-4. https://doi.org/10.1007/s11625-018-0651-5

Sandbrook, C., Fisher, J. A., Holmes, G., Luque-Lora, R., \& Keane, A. (2019). The global conservation movement is diverse but not divided. Nature Sustainability, 2(4), 316-323. https://doi.org/10.1038/s4189 3-019-0267-5

Sarkki, S., Niemela, J., Tinch, R., van den Hove, S., Watt, A., \& Young, J. (2014). Balancing credibility, relevance and legitimacy: A critical assessment of trade-offs in science-policy interfaces. Science and Public Policy, 41(2), 194-206. https://doi.org/10.1093/scipol/sct046

Sarkki, S., Tinch, R., Niemelä, J., Heink, U., Waylen, K., Timaeus, J., ... van den Hove, S. (2015). Adding 'iterativity' to the credibility, relevance, legitimacy: A novel scheme to highlight dynamic aspects of science-policy interfaces. Environmental Science and Policy, 54, 505512. https://doi.org/10.1016/j.envsci.2015.02.016

Scarano, F. R., Padgurschi, M. C. G., Pires, A. P. F., Castro, P. F. D., Farinaci, J. S., Bustamante, M., ... Joly, C. A. (2019). Increasing effectiveness of the science-policy interface in the socioecological arena in Brazil. Biological Conservation, 240, 108227. https://doi.org/10.1016/j. biocon.2019.108227

Schirrmeister, E., Göhring, A.-L., \& Warnke, P. (2020). Psychological biases and heuristics in the context of foresight and scenario processes. Futures \& Foresight Science, 2(2), 1-18. https://doi.org/10.1002/ ffo 2.31

Sharpe, B. (2013). Three horizons: The patterning of hope. Charmouth, UK: Triarchy Press.

Sharpe, B., Hodgson, A., Leicester, G., Lyon, A., \& Fazey, I. (2016). Three horizons: A pathways practice for transformation. Ecology and Society, 21(2), 210247. https://doi.org/10.5751/ES-08388-210247

Star, S. L., \& Griesemer, J. R. (1989). Institutional ecology, translations' and boundary objects: Amateurs and professionals in Berkeley's Museum of Vertebrate Zoology, 1907-39. Social Studies of Science, 19(3), 387-420. https://doi.org/10.1177/030631289019003001 
Steffen, W., Rockström, J., Richardson, K., Lenton, T. M., Folke, C., Liverman, D., ... Schellnhuber, H. J. (2018). Trajectories of the earth system in the anthropocene. Proceedings of the National Academy of Sciences of the United States of America, 115(33), 8252-8259. https:// doi.org/10.1073/pnas.1810141115

Stevens, C. J., Fraser, I., Mitchley, J., \& Thomas, M. B. (2007). Making ecological science policy-relevant: Issues of scale and disciplinary integration. Landscape Ecology, 22(6), 799-809. https://doi.org/10.1007/ s10980-007-9092-8

Tadaki, M., Sinner, J., \& Chan, K. M. A. (2017). Making sense of environmental values: A typology of concepts. Ecology and Society, 22(1), art7. https://doi.org/10.5751/ES-08999-220107

TEEB. (2010). The economics of ecosystems \& biodiversity: Mainstreaming the economics of nature: A synthesis of the approach, conclusions and recommendations of TEEB. De Economist. Valleta, Malta: Progress Press.

TEEB. (2018). Measuring what matters in agriculture and food systems: $A$ synthesis of the results and recommendations of TEEB for Agriculture and Food's Scientific and Economic Foundations report. Geneva, Switzerland: TEED.

Tengö, M., Brondizio, E. S., Elmqvist, T., Malmer, P., \& Spierenburg, M. (2014). Connecting diverse knowledge systems for enhanced ecosystem governance: The multiple evidence base approach. Ambio, 43(5), 579-591. https://doi.org/10.1007/s13280-014-0501-3

Tengö, M., Hill, R., Malmer, P., Raymond, C. M., Spierenburg, M., Danielsen, F., ... Folke, C. (2017). Weaving knowledge systems in IPBES, CBD and beyond-Lessons learned for sustainability. Current Opinion in Environmental Sustainability, 26-27, 17-25. https://doi. org/10.1016/j.cosust.2016.12.005

Turnhout, E., Dewulf, A., \& Hulme, M. (2016). What does policy-relevant global environmental knowledge do? The cases of climate and biodiversity. Current Opinion in Environmental Sustainability, 18, 65-72. https://doi.org/10.1016/j.cosust.2015.09.004

Tzoulas, K., Korpela, K., Venn, S., Yli-Pelkonen, V., Kaźmierczak, A., Niemela, J., \& James, P. (2007). Promoting ecosystem and human health in urban areas using Green Infrastructure: A literature review. Landscape and Urban Planning, 81(3), 167-178. https://doi. org/10.1016/j.landurbplan.2007.02.001

UNEP. (2010). Decisions adopted by the conference of the parties to the convention on biological diversity at its tenth meeting. The strategic plan for Biodiversity 2011-2020 and the Aichi Biodiversity Targets. UNEP/CBD/COP/DEC/X/2. UNEP, Nagoya, Japan.

UNEP. (2019). Global Environmental Outlook (GEO-6): Healthy planet, healthy people (P. Ekins, J. Gupta, J. Bemigisha, \& K. Jiang, Eds.). Cambridge, UK: Cambridge University Press.
Vadrot, A. B., Jetzkowitz, J., \& Stringer, L. C. (2016). Social sciences: IPBES disciplinary gaps still gaping. Nature, 530(7589), 160. https:// doi.org/10.1038/530160b

Vadrot, A. B. M., Rankovic, A., Lapeyre, R., Aubert, P.-M., \& Laurans, Y. (2018). Why are social sciences and humanities needed in the works of IPBES? A systematic review of the literature. Innovation: The European Journal of Social Science Research, 31(S1), 78-100. https:// doi.org/10.1080/13511610.2018.1443799

Van der Merwe, S. E., Biggs, R., Preiser, R., Cunningham, C., Snowden, D. J., O'Brien, K., ... Goh, Z. (2019). Making sense of complexity: Using sensemaker as a research tool. Systems, 7(2), 25. https://doi. org $/ 10.3390 /$ systems 7020025

Wiek, A., \& Iwaniec, D. (2014). Quality criteria for visions and visioning in sustainability science. Sustainability Science, 9(4), 497-512. https:// doi.org/10.1007/s11625-013-0208-6

Wilson, E. O. (2016). Half-earth: Our planet's fight for life. New York, NY: Liverwright Publishing Corporation.

Wise, R. M., Fazey, I., Stafford Smith, M., Park, S. E., Eakin, H. C., Archer Van Garderen, E. R. M., \& Campbell, B. (2014). Reconceptualising adaptation to climate change as part of pathways of change and response. Global Environmental Change, 28, 325-336. https://doi. org/10.1016/j.gloenvcha.2013.12.002

Wyborn, C., Davila, F., Pereira, L., Lim, M., Alvarez, I., Henderson, G., ... Woods, E. (2020). Imagining transformative biodiversity futures. Nature Sustainability. https://doi.org/10.1038/s41893-0200587-5

Zurek, M. B., \& Henrichs, T. (2007). Linking scenarios across geographical scales in international environmental assessments. Technological Forecasting and Social Change, 74, 1282-1295. https:// doi.org/10.1016/j.techfore.2006.11.005

\section{SUPPORTING INFORMATION}

Additional supporting information may be found online in the Supporting Information section.

How to cite this article: Pereira LM, Davies KK, den Belder E, et al. Developing multiscale and integrative nature-people scenarios using the Nature Futures Framework. People Nat. 2020;2:1172-1195. https://doi.org/10.1002/pan3.10146 